\title{
Small Reactor Designs Suitable for Direct Nuclear Thermal Propulsion: Interim Report
}

Bruce G. Schnitzler

January 2012

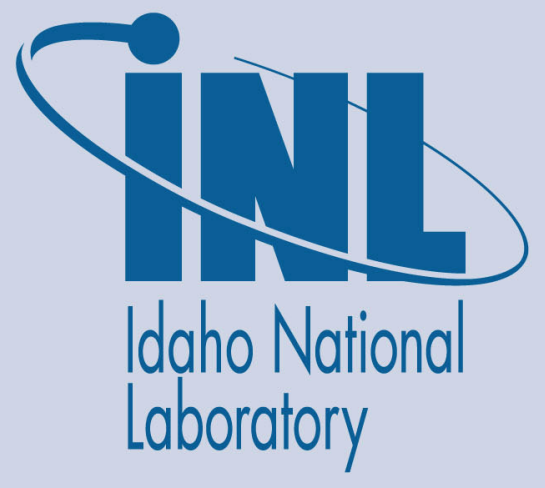

The INL is a U.S. Department of Energy National Laboratory operated by Battelle Energy Alliance 


\section{DISCLAIMER}

This information was prepared as an account of work sponsored by an agency of the U.S. Government. Neither the U.S. Government nor any agency thereof, nor any of their employees, makes any warranty, expressed or implied, or assumes any legal liability or responsibility for the accuracy, completeness, or usefulness, of any information, apparatus, product, or process disclosed, or represents that its use would not infringe privately owned rights. References herein to any specific commercial product, process, or service by trade name, trade mark, manufacturer, or otherwise, does not necessarily constitute or imply its endorsement, recommendation, or favoring by the U.S. Government or any agency thereof. The views and opinions of authors expressed herein do not necessarily state or reflect those of the U.S. Government or any agency thereof. 


\title{
Small Reactor Designs Suitable for Direct Nuclear Thermal Propulsion: Interim Report
}

\author{
Bruce G. Schnitzler
}

January 2012

\begin{abstract}
Idaho National Laboratory
Space Nuclear Systems and Technologies Division Idaho Falls, Idaho 83415
\end{abstract}

http://www.inl.gov

Prepared for the

U.S. Department of Energy

Office of Nuclear Energy

Under DOE Idaho Operations Office

Contract DE-AC07-05ID14517 


\section{CONTENTS}

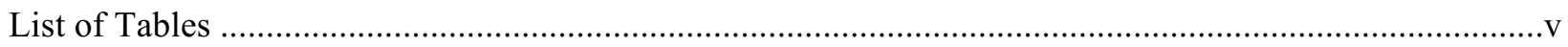

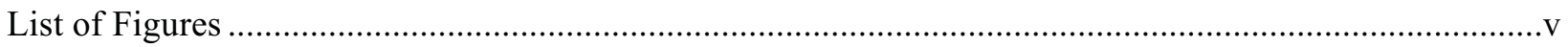

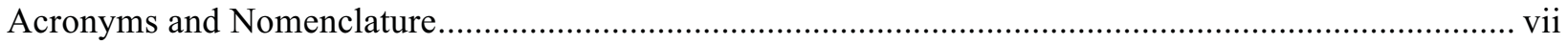

1. Introduction 1

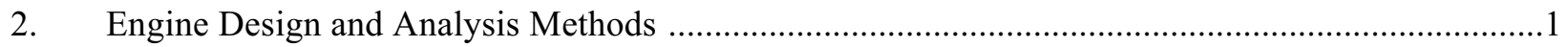

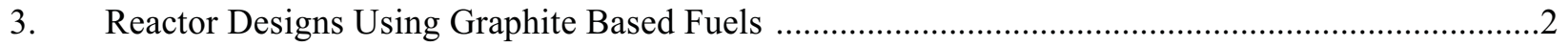

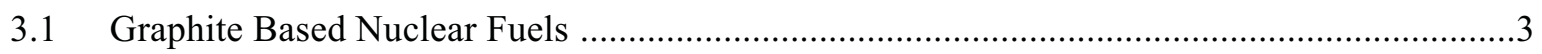

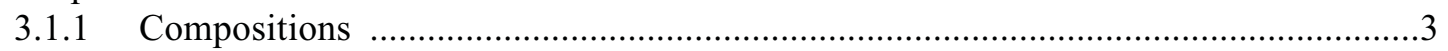

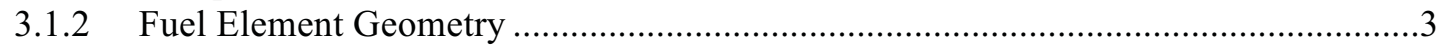

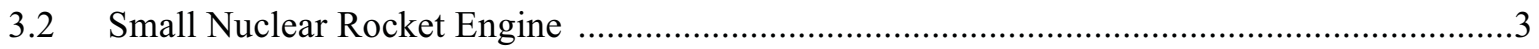

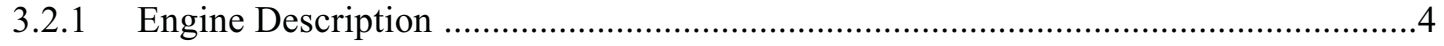

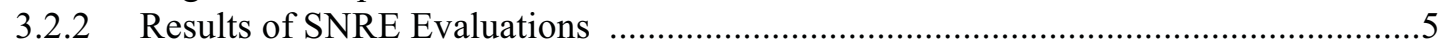

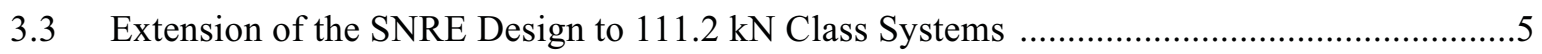

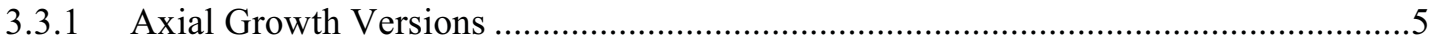

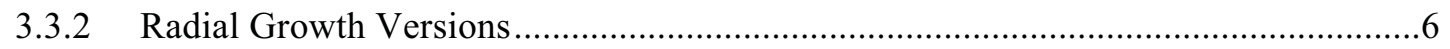

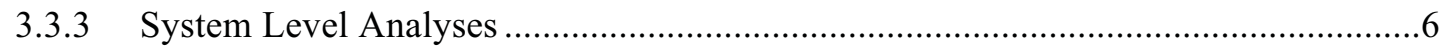

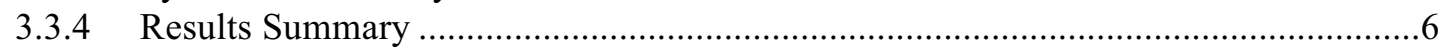

3.4 Extension of the SNRE Design to Lower Thrust Systems .................................................

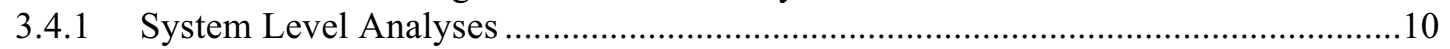

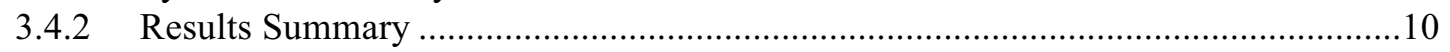

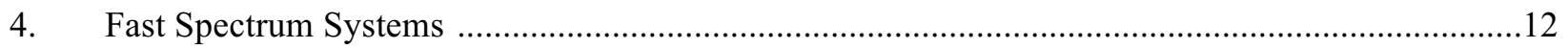

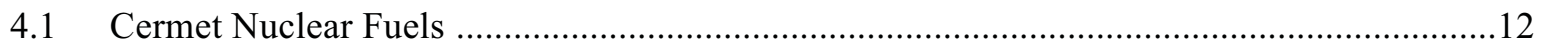

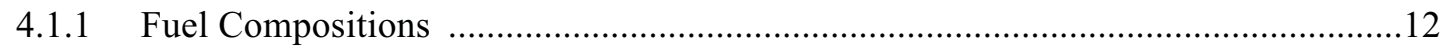

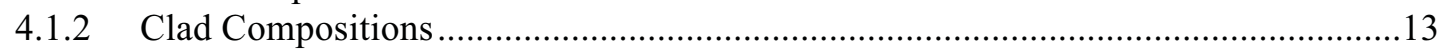

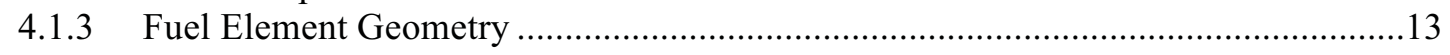

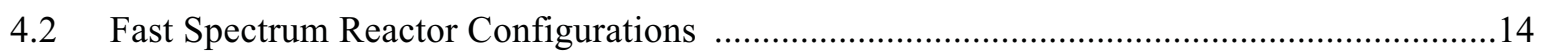

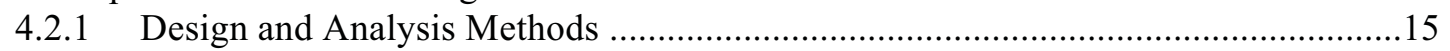

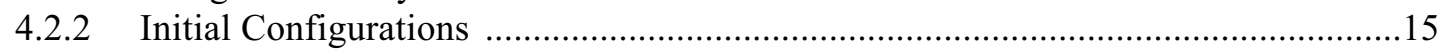

4.3 Neutronics Results for Criticality Limited Fast Spectrum Reactor Configurations ...............16

4.3.1 Configurations Based on ANL Heritage Cermet Designs .........................................16

4.3.2 Configurations Based on the GE-710 Heritage Cermet Design ................................17

4.3.3 Configurations Based on Pratt and Whitney Proposed Cermet Fuel Element

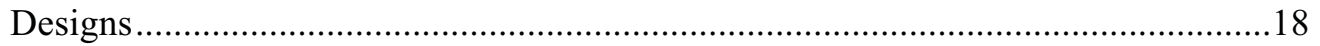

4.3.4 Configurations Using Cermet Fueled Elements Duplicating the NERVA Hexagonal Element Geometry ........................................................................... 19

4.4 Preliminary Estimates of System Level Performance for Criticality Limited Fast

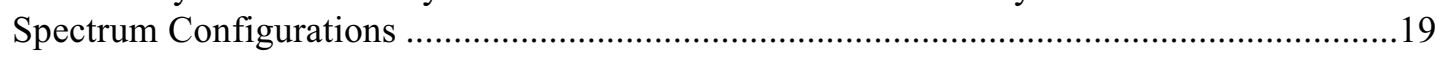

4.5 Neutronics Results for Fast Spectrum Systems in the $111.2 \mathrm{kN}\left(25,000-\mathrm{lb}_{\mathrm{f}}\right)$ Thrust

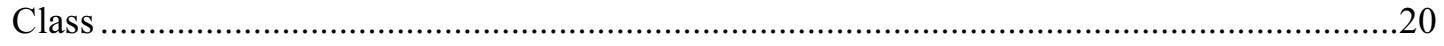

4.5.1 Configurations Based on the ANL-200 Heritage Cermet Design ............................21 
4.5.2 Configurations Based on the GE-710 Heritage Cermet Design .

4.6 Preliminary Estimates of System Level Performance for $111.2 \mathrm{kN}$ (25,000-lbf) Class Configurations

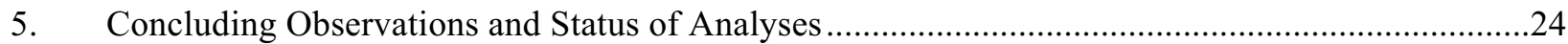

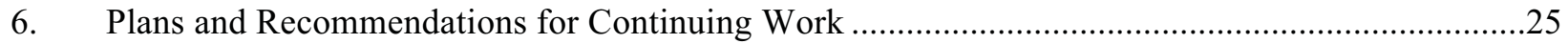

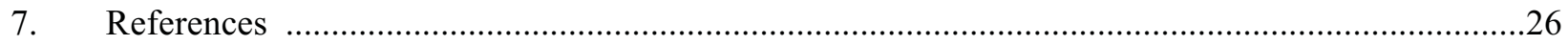




\section{FIGURES}

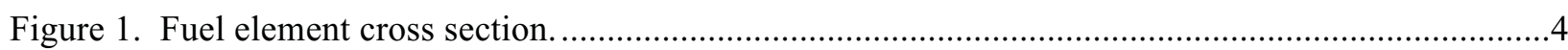

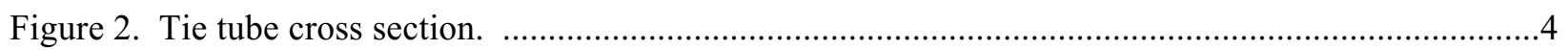

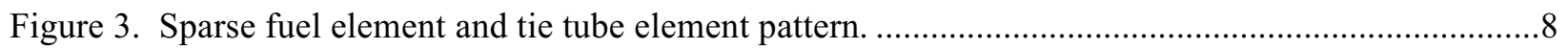

Figure 4. SNRE fuel element and tie tube element pattern. ............................................................

Figure 5. Dense fuel element and tie tube element pattern. …......................................................

Figure 6. Cross sections near core mid-plane for three lower thrust engines based on the SNRE design (same scale for all three concepts). .........................................................................

\section{TABLES}

Table 1. Performance characteristics of $111.2 \mathrm{kN}$ engines based on growth versions of the SNRE

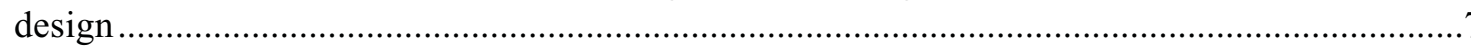

Table 2. Reactor parameters for several engine configurations based on the SNRE design ......................9

Table 3. Performance characteristics of lower thrust engine designs based on the SNRE .......................11

Table 4. Hexagonal fuel element geometry data for proposed propulsion engine concepts......................13

Table 5. Hexagonal fuel element geometry data in traditional engineering units for proposed propulsion engine concepts

Table 6. Characteristics of selected reactor configurations based on ANL heritage cermet fuel designs

Table 7. Characteristics of selected reactor configurations based on the GE-710 heritage cermet fuel design

Table 8. Characteristics of selected reactor configurations based on proposed Pratt and Whitney cermet fuel element designs

Table 9. Configurations using cermet fueled elements duplicating the NERVA hexagonal element geometry 
Table 10. Preliminary estimates of system level performance for criticality limited fast spectrum configurations.

Table 11. Characteristics of selected reactor configurations based on the ANL-210 heritage cermet fuel design

Table 12. Characteristics of selected reactor configurations based on the GE-710 heritage cermet fuel design .....

Table 13. Preliminary estimates of system level performance for $111.2 \mathrm{kN}(25,000 \mathrm{lbf})$ class configurations.

Table 14. Status of analyses by analysis phase, reactor type, and thrust level 


\section{ACRONYMS}

AEC (United States) Atomic Energy Commission

AIAA American Institute of Aeronautics and Astronautics

ANL Argonne National Laboratory, Argonne, Illinois

cermet ceramic-metallic, generally fuel containing uranium in a refractory metal alloy matrix

DoD (United States) Department of Defense

DOE (United States) Department of Energy

DRA Design Reference Architecture

ENDF/B (United States) Evaluated Nuclear Data File

GE General Electric

Isp specific impulse (seconds)

JPC Joint Propulsion Conference

k-eff effective multiplication factor

$\mathrm{K} \quad$ temperature (Kelvin)

$\mathrm{lb}_{\mathrm{f}} \quad$ pounds thrust

$\mathrm{lb}_{\mathrm{m}} \quad$ pounds mass

MCNP Monte Carlo N-Particle transport code

$\mathrm{MPa} \quad$ pressure (megapascals)

MWth thermal power (megawatts)

NASA (United States) National Aeronautics and Space Administration

NEDS Nuclear Engine Definition Study

NESS Nuclear Engine System Simulation code

NERVA Nuclear Engine for Rocket Vehicle Applications

NF Nuclear Furnace

NRX NERVA Experimental Reactor

NRX-EST Nuclear Reactor Experimental - Engine System Test

NTR/NTP Nuclear Thermal Rocket / Nuclear Thermal Propulsion

SDI Strategic Defense Initiative

SEI Strategic Exploration Initiative

SNPO Space Nuclear Propulsion Office (Joint AEC - NASA)

SNRE Small Nuclear Rocket Engine

TRL technology readiness level

XE experimental engine (also XE Prime and XE') 


\section{Small Reactor Designs Suitable for Direct Nuclear Thermal Propulsion}

\section{Introduction}

Advancement of U.S. scientific, security, and economic interests requires high performance propulsion systems to support missions beyond low Earth orbit. A robust space exploration program will include robotic outer planet and crewed missions to a variety of destinations including the moon, near Earth objects, and eventually Mars. Past studies, in particular those in support of both the Strategic Defense Initiative (SDI) and the Space Exploration Initiative (SEI), have shown nuclear thermal propulsion systems provide superior performance for high mass high propulsive delta-V missions. In NASA's recent Mars Design Reference Architecture (DRA) 5.0 study $^{1}$, nuclear thermal propulsion (NTP) was again selected over chemical propulsion as the preferred in-space transportation system option for the human exploration of Mars because of its high thrust and high specific impulse ( $900 \mathrm{~s})$ capability, increased tolerance to payload mass growth and architecture changes, and lower total initial mass in low Earth orbit. The recently announced national space policy ${ }^{2}$ supports the development and use of space nuclear power systems where such systems safely enable or significantly enhance space exploration or operational capabilities.

In the DRA 5.0 study, a common nuclear thermal propulsion stage with three $111.2 \mathrm{kN}\left(25,000 \mathrm{lb}_{\mathrm{f}}\right)$ engines was used for all primary mission maneuvers. Moderately lower thrust engines may also have important roles. Robotic science missions could benefit directly from smaller nuclear engines, even when NTP is not considered enabling for the particular mission or class of missions. Smaller nuclear engines are also more attractive for an in-space nuclear propulsion technology demonstrator prior to larger scale use for cargo and crewed exploration missions. The lower thrust engine designs could then be used to demonstrate critical technologies that are directly extensible to higher thrust levels.

An extensive nuclear thermal rocket technology development effort was conducted under the Rover/NERVA ${ }^{3}$, GE-710 ${ }^{4}$ and ANL $^{5}$ nuclear rocket programs (1955-1973). Both graphite and refractory metal alloy fuel types were pursued. ${ }^{6}$ The primary and significantly larger Rover/NERVA program focused on graphite type fuels. Research, development, and testing of high temperature graphite fuels was conducted. Reactors and engines employing these fuels were designed, built, and ground tested.

The GE-710 and ANL programs focused on an alternative ceramic-metallic "cermet" fuel type consisting of $\mathrm{UO}_{2}$ (or $\mathrm{UN}$ ) fuel embedded in a refractory metal matrix such as tungsten. The General Electric program examined closed loop concepts for space or terrestrial applications as well as open loop systems for direct nuclear thermal propulsion. Although a number of fast spectrum reactor and engine designs suitable for direct nuclear thermal propulsion were proposed and designed, none were built.

This interim report summarizes status as of January 31, 2012.

\section{Engine Design and Analysis Methods}

Engine design and analysis requires consideration and evaluation of neutronic performance, the combined thermal-fluid-structural performance of reactor interior components, and engine system level performance. An effective design and analysis sequence is to first establish a preliminary core configuration that meets the fundamental neutronic performance requirements of criticality and adequate control swing. Results from neutronic analyses of the reactor core can then be utilized to provide neutron and gamma energy deposition rates as input to integrated thermal-fluid-structural analyses of the core 
interior components. Once acceptable neutronic and thermal performance is achieved, overall engine system performance can be evaluated. The above sequence is typically an iterative process.

Preliminary core configurations typically employ fuel elements with fixed fuel composition and fissile material enrichment. Uniform fuel loading usually results in undesirable radial power and temperature profiles in the engine. Engine performance can be improved by some combination of propellant flow control at the fuel element level and by varying the fuel composition. Enrichment zoning at the fuel element level with lower enrichments in the higher power elements at the core center and on the core periphery is particularly effective. Power flattening by enrichment zoning typically results in more uniform propellant exit temperatures and improved engine performance at the cost of some reactivity loss. Compensation for the reactivity loss is possible by several methods. Again, an iterative process is usually needed.

Another important step in the design and analysis sequence is to evaluate fissile depletion and fission product buildup during engine operation. Engine operating times are usually short with low reactivity loss. Reactivity losses due to depletion can be accommodated by control drum rotation, but drum rotation also results in core power distribution changes that can lower engine performance.

Historically, a variety of analytic methods have been utilized in the design and performance evaluations of nuclear thermal propulsion systems. The most important have been Monte Carlo, onedimensional and multi-dimensional discrete ordinates transport, and point-kernel methods. The selection of both analytic methods and the level of modeling detail to be employed are influenced by several factors including model development time, available computational capacity, and the intended application of the results. Lower fidelity solutions may often suffice for some scoping studies such as preliminary engine sizing. At the other end of the spectrum is the reactor equivalent of modern aircraft design where a vehicle may be flown computationally as an integral part of the design process.

All transport evaluations reported here were performed using the MCNP Monte Carlo transport code. ${ }^{7}$ Cross section data employed in the MCNP transport calculations are primarily from the Evaluated Nuclear Data File ${ }^{8.9}$ (ENDF/B) Versions V and VI. The ENDF/B cross section evaluations for some materials of interest, in particular the zirconium and hafnium isotopes, do not include photon yield data. The ENDF/B evaluations were employed for estimating core reactivity and alternate Lawrence Livermore evaluations ${ }^{18}$ for some materials substituted for energy deposition evaluations.

\section{Reactor Designs Using Graphite Based Fuels}

Numerous reactor and engine tests were conducted between 1959 and 1973 as part of the Rover/NERVA program. The reactor and engine designs all utilized graphite based fuel forms and highly enriched ${ }^{235} \mathrm{U}$. Koenig ${ }^{3}$ provides a detailed summary of the reactors constructed and a chronology of specific tests. Dewar ${ }^{11}$ provides a most comprehensive history from the perspective of a nuclear policy specialist. A paper by Robbins and Finger ${ }^{12}$ summarizes the program history from the perspective the Space Nuclear Propulsion Office that managed the program.

Figure 6 of Reference 3 identifies 22 reactor test articles. Multiple tests were conducted with some of the test articles. Eighteen of the test articles may be classified as reactor experiments and two as nuclear propulsion engine tests. Two cold flow tests were conducted with no nuclear operation. The NRX/EST test combined a reactor test with an engine system demononstration. ${ }^{12,3}$ Two critical components, the turbopump and nozzle, were included although in a different layout than would be used for a flight engine. The second and final engine test ${ }^{12}$ was the Ground Experimental Engine, the XE or XE-Prime.

Pewee ${ }^{13}$ was a small reactor designed to serve as a test bed for full sized fuel elements and other reactor components but requiring a substantially lower number of fuel elements than the earlier reactors. Pewee 1 contained 402 fuel elements. The last reactor test of the program was the Nuclear Furnace 1 
(NF-1), designed specifically for economical fuels testing. ${ }^{3,14}$ The NF-1 had a nominal design power of 44 MWth and contained only 49 fuel elements. The ability to achieve criticality with such a low fuel inventory was enabled by incorporating light water as the moderator into the reactor core design. The NF-1 experiments also successfully demonstrated an effluent cleanup system. Fuels development and engine development activities had been carried out in parallel early in the program with complete engine tests effectively serving as fuels development tests. Both Pewee and the Nuclear Furnace enabled fuels testing with lower costs, shorter lead times, and with fewer fuel elements required.

\subsection{Graphite Based Nuclear Fuels}

\subsubsection{Compositions}

$\mathrm{Taub}^{15}$ has summarized graphite based fuels development for propulsion engines. The very early fuel forms consisted of uncoated $\mathrm{UO}_{2}$ or $\mathrm{UC}_{2}$ particles dispersed in a graphite matrix. Reactor tests in the period 1964 - 1969 employed $\mathrm{UC}_{2}$ particles with pyrolytic graphite coatings. These pyrolytic graphite coatings only provided chemical stability during lower temperature processing. The coatings were not intended to prevent fission product loss during high temperature operation. Two promising fuel types were developed toward the end of the development program. These are the pure $(\mathrm{U}, \mathrm{ZrC})$ carbide fuel and the $(\mathrm{U}, \mathrm{ZrC}) \mathrm{C}$-graphite "composite" fuel described by Taub. Both fuel types were tested ${ }^{16}$ in the Nuclear Furnace 1 test reactor.

\subsubsection{Fuel Element Geometry}

Fuel element geometries employed in the early reactor experiments included plates and extruded cylindrical rods with four and later seven propellant channels. Engine designs intended as flight prototypes all employed extruded hexagonal fuel elements. By the end of the development program, a standard fuel element geometry had been adopted. The hexagonal element was $1.905 \mathrm{~cm}(0.750 \mathrm{in})$ across the flats and contained 19 propellant channels.

Composite fuel elements underwent irradiation testing in the Nuclear Furnace at peak power densities of $\sim 4500-5000 \mathrm{MW} / \mathrm{m}^{3}$ and hydrogen exhaust temperatures of $\sim 2450 \mathrm{~K}$ for $\sim 2$ hours. They are expected to perform satisfactorily for $\sim 2-4$ hours at exhaust temperatures of $\sim 2500-2800 \mathrm{~K}$. Composite fuel also has a higher coefficient of thermal expansion that more closely matches that of its zirconium carbide $(\mathrm{ZrC})$ coating helping to reduce coating cracks and hydrogen erosion of the graphite. More than 20 reactors and engines employing graphite based fuels were designed, built, and ground tested.

\subsection{Small Nuclear Rocket Engine}

The Small Nuclear Rocket Engine (SNRE) was the last engine design studied by the Los Alamos National Laboratory during the Rover/NERVA program. At the time, this engine was a state-of-the-art design incorporating lessons learned from the very successful technology development program. Although the program was terminated prior to completion of the design, the available preliminary design results provided reasonably good documentation, especially for the reactor core. Activities at the NASA Glenn Research Center included upgrading and modernizing nuclear thermal propulsion system models and analysis methods. Initial efforts were focused on benchmarking methods and models against the SNRE and stage configuration documented in the Nuclear Engine Definition Study (NEDS) Preliminary reports. ${ }^{17,18}$ 


\subsubsection{Engine Description}

Design requirements for the small engine included the ability to operate at either of two full power conditions. Full power operating conditions for a single-mission injection mode are one-hour engine life at $367 \mathrm{MW}$ th yielding $73.0 \mathrm{kN}\left(16,406 \mathrm{lb}_{\mathrm{f}}\right)$ thrust with a specific impulse of 875 seconds. Full power conditions for operation in a reusable mission mode are two-hour engine life at $354 \mathrm{MWth}$ yielding $71.7 \mathrm{kN}\left(16,125 \mathrm{lb}_{\mathrm{f}}\right)$ thrust with a specific impulse of 860 seconds. Engine specific impulse is a function of several parameters including propellant molecular weight, propellant temperature, and nozzle expansion ratio. The SNRE nozzle expansion ratio of 100:1 was established primarily by the requirement that the stage be carried into earth orbit by the then planned space shuttle. Hydrogen propellant chamber temperatures are $2696 \mathrm{~K}$ and $2633 \mathrm{~K}$, respectively, for the two operating modes.

The engine utilizes hexagonal fuel elements and hexagonal structural support or "tie tube" elements. Both element types are $1.905 \mathrm{~cm}(0.750$ in) across the flats and $89 \mathrm{~cm}(\sim 35 \mathrm{in})$ in length. The fuel element geometry cross-section is shown in Figure 1. Fuel elements contain 19 propellant channels with a $0.2565-\mathrm{cm}(0.101-\mathrm{in})$ borehole diameter. The boreholes are located on a $0.4089-\mathrm{cm}(0.161$-in) pitch. The hexagonal outer surfaces are coated with a 50 micrometer thick $\mathrm{ZrC}$ protective layer. The borehole inner protective coating is also $\mathrm{ZrC}$ and varies from about 50 micrometer at the inlet to about 150 micrometer at the outlet end. A uniform 100 micrometer thickness of inner borehole $\mathrm{ZrC}$ cladding is assumed for MCNP models.

The fuel composition is the (U,Zr)C-graphite composite described by Taub. ${ }^{15}$ The reference SNRE engine design was based on composite fuel with a $(\mathrm{U}, \mathrm{Zr}) \mathrm{C}$ solid solution content of $35 \%$ by volume. In the initial design effort, evaluations were first performed assuming a uniform uranium loading of $0.64 \mathrm{~g} / \mathrm{cm}^{3}$. Element uranium loadings were then selectively reduced in the higher power elements to flatten the radial fission profile across the core.

Regeneratively cooled tie tube elements provide structural support for the fuel elements, provide a source of energy to drive the turbomachinery, and incorporate a zirconium hydride moderator sleeve to raise neutronic reactivity in the small engine size. The tie tube element cross-section geometry is shown in Figure 2. Working outward from the center, the six cylindrical regions shown are inlet (aft-flowing) hydrogen, inner tie tube, zirconium hydride moderator, outlet (forward-flowing) hydrogen, outer tie tube, and a porous $\mathrm{ZrC}$ insulator. The inner and outer tie tubes must support and transmit the entire core axial pressure drop through the fuel elements. Based on calculated loads and operating temperatures, Inconel-718 was selected for the preliminary SNRE design.

The core contains 564 fuel elements and 241 tie tube elements. Additional complete and partial hexagonal elements of beryllium "filler" elements are utilized to complete an approximately cylindrical core.

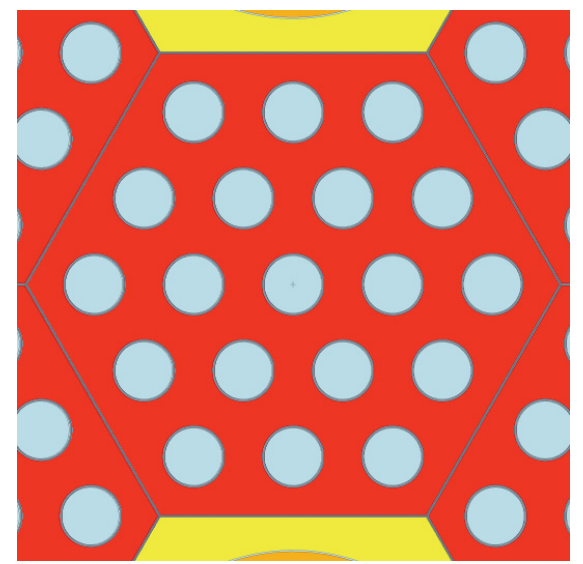

Figure 1. Fuel element cross section.

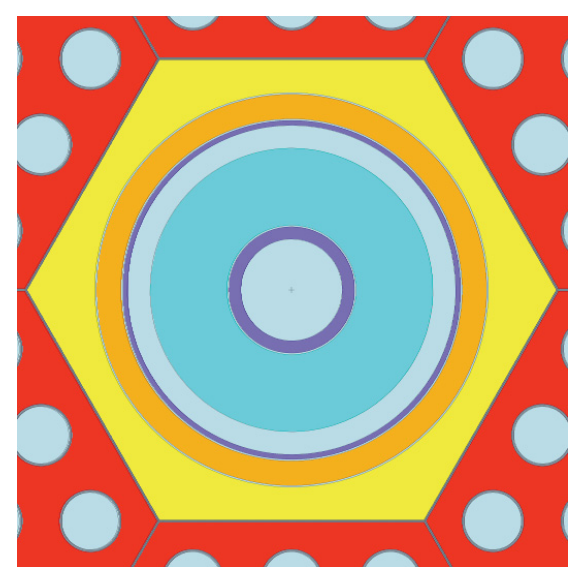

Figure 2. Tie tube cross section. 


\subsubsection{Results of SNRE Evaluations}

Methods development and benchmarking activities using the SNRE have been documented primarily in American Institute of Aeronautics and Astronautics (AIAA) Joint Propulsion Conference (JPC) papers. These papers have addressed neutronics modeling of the SNRE reactor core, ${ }^{19}$ enrichment zoning options $^{20}$ for the SNRE, the SNRE reference stage, ${ }^{21}$ integrated thermal-fluid-structural analysis of reactor core interior components, ${ }^{22}$ and engine system level modeling and analyses. ${ }^{23}$ A prior year effort included an extension of the SNRE design into the $111.2 \mathrm{kN}\left(25,000 \mathrm{lb}_{\mathrm{f}}\right)$ thrust range. ${ }^{24}$ Relevant extracts from the previously reported $111.2 \mathrm{kN}$ evaluations results are summarized in Section 3.4. Current year efforts have included evaluation of lower thrust systems based on the SNRE design with results reported in Section 3.5.

\subsection{Extension of the SNRE Design to $111.2 \mathrm{kN}$ Class Systems}

The primary motivation for current interest in $111.2 \mathrm{kN}$ class systems is the DRA 5.0 study use of a common nuclear thermal propulsion stage with three $111.2 \mathrm{kN}$ engines for all primary mission maneuvers. Two relatively straightforward options were considered for extending the SNRE-based engine design into the $111.2 \mathrm{kN}$ thrust range. The first option was to simply extend the reactor core active fuel length while retaining all other components identical to the SNRE engine. The second option was to retain the SNRE core length but expand the effective core radius by adding additional hexagonal fuel and tie tube elements. Simple scaling based on needed thermal power was utilized to obtain preliminary estimates of core length for the axial growth versions and preliminary estimates of the number of additional fuel and tie tube elements for the radial growth versions.

\subsubsection{Axial Growth Versions}

The $73.0 \mathrm{kN}\left(16,406 \mathrm{lb}_{\mathrm{f}}\right)$ SNRE engine operating power was $367 \mathrm{MWth}$. Simple scaling implies the operating power required for a $111.2 \mathrm{kN}\left(25,000 \mathrm{lb}_{\mathrm{f}}\right)$ thrust engine will be approximately $550 \mathrm{MWth}$. Maintaining the same linear power density in the active fuel would dictate a 135.4-cm (53.3-in) active fuel length. During the Rover/NERVA Program a 132.1-cm (52-in) long hexagonal fuel element had emerged as a standard and this length was selected for the axial growth version.

Lengthening the SNRE reactor core to $132.1 \mathrm{~cm}$ and retaining a uranium loading of $0.60 \mathrm{~g} / \mathrm{cm}^{3}$ with a constant ${ }^{235} \mathrm{U}$ enrichment of $93 \mathrm{wt} \%$ yielded a reactor k-eff of 1.0799 with the control drums set at the middle of their rotation range. Two performance enhancing options to take credit for this significant excess reactivity are reducing the beryllium reflector thickness and reducing the uranium fissile loading. Decreasing the reflector thickness and control cylinder dimensions reduces engine mass and improves the engine thrust-to-weight. Reducing the $14.73-\mathrm{cm}(5.80$-in) thick reflector to a $7.112-\mathrm{cm}(2.80$-in) thick reflector yielded a reactor k-eff of 1.0297 and considerable mass savings. Unfortunately, the smaller control cylinders did not provide an adequate reactivity control swing. Although control cylinder redesign or additional control cylinders could presumably provide adequate control swing, this option was not pursued.

Reducing uranium loading in the $(\mathrm{U}, \mathrm{Zr}) \mathrm{C}$ solid solution composite fuel lowers core reactivity and also raises the composite fuel melting point. Credit for the higher melting point can be taken either as additional margin to fuel melting or as increased hydrogen propellant temperature. Reducing uranium loading to $0.25 \mathrm{~g} / \mathrm{cm}^{3}$ yielded a reactor k-eff of 1.0114 and reducing to $0.20 \mathrm{~g} / \mathrm{cm}^{3}$ yielded a reactor k-eff of 0.9922 . The $0.25 \mathrm{~g} / \mathrm{cm}^{3}$ loading was adopted for the axial growth version engine. 


\subsubsection{Radial Growth Versions}

The average fuel element power in the 88.9-cm) 35-in long SNRE design was approximately 0.65 MWth. Maintaining the same fuel element power in a radial growth version would dictate approximately 860 fuel elements for a $111.2 \mathrm{kN}\left(25,000 \mathrm{lb}_{\mathrm{f}}\right)$ thrust engine operating at $550 \mathrm{MWth}$.

The SNRE design incorporated a fuel element and tie tube element pattern in the core interior that differed from the pattern typically used for larger engines. Core reactivity limitations tended to be more constraining in small engine designs. Given a proposed engine design with a fixed number of fuel elements, the core reactivity could be raised by incorporating additional tie tube elements. The more reactive fuel element and tie tube element pattern, used in the Pewee and SNRE designs and identified here by the term "SNRE" pattern, provided additional reactivity at the expense of a larger effective core radius. The pattern typically used for larger engines and identified here by the term "sparse" pattern, results in a lower effective core radius and is preferred if adequate reactivity is available.

An important feature common to both patterns is that each tie tube is surrounded by, and provides mechanical support for, six fuel elements. With the SNRE pattern, each fuel element has three adjacent fuel elements and three adjacent tie tube elements making up the six surrounding elements. With the sparse pattern, each fuel element has two adjacent tie tubes and four adjacent fuel elements.

The sparse pattern was selected for the radial growth engine. An initial core configuration was developed containing 864 fuel elements, 283 tie tube elements, and 138 complete or partial beryllium filler elements. All radial components outside the active core region were similar to the SNRE design. The radial thickness of each component was preserved. Initial MCNP neutronics evaluation assuming a constant uranium loading of $0.60 \mathrm{~g} / \mathrm{cm}^{3}$ and a flat ${ }^{235} \mathrm{U}$ enrichment of $93 \mathrm{wt} \%$ yielded a reactor k-eff of 1.0348 with the control drums set at the middle of their rotation range.

As noted previously for the axial growth version, two options are available to take credit for the excess reactivity. Reducing the reflector thickness was not evaluated. Reducing uranium loading to $0.45 \mathrm{~g} / \mathrm{cm}^{3}$ yielded a k-eff of 1.0067 .

\subsubsection{System Level Analyses}

Engine performance was evaluated by NASA Glenn using the Nuclear Engine System Simulation (NESS) code. $^{23}$ The NESS code contains an option to calculate a suitable fuel element propellant orificing pattern to minimize fuel element temperature peaking, maintain the peak fuel temperature below a specified limit, and maximize the mixed mean propellant exit temperature. This option may be exercised at any point during the enrichment zoning process. Comparisons of system level performance before and after enrichment zoning were previously reported ${ }^{20}$ for the SNRE design. Identical specific impulse and comparable engine thrust were achievable before and after enrichment zoning. Radial power peaking prior to enrichment zoning results in somewhat higher pump discharge pressure requirements and marginally higher engine system masses.

\subsubsection{Results Summary}

Performance characteristics for two of the $111.2 \mathrm{kN}\left(25,000-\mathrm{lb}_{\mathrm{f}}\right)$ engine options evaluated are shown in Table 1. Characteristics baselined in the Mars DRA 5.0 Study and for the SNRE design are included for comparison. Both axial growth and radial growth engine options were evaluated at two different operating conditions identified as "nominal" and "enhanced" in Table 1 . The $2860 \mathrm{~K}$ maximum fuel temperature assumed for the SNRE baseline was imposed for the nominal operating condition cases. For the enhanced operating condition cases, the same $40 \mathrm{~K}$ margin to fuel melting as assumed for the SNRE was imposed allowing somewhat higher fuel operating temperatures at the reduced fissile loadings. 
Table 1. Performance characteristics of $111.2 \mathrm{kN}$ engines based on growth versions of the SNRE design.

\begin{tabular}{|c|c|c|c|c|c|c|}
\hline \multirow[b]{2}{*}{ Performance Characteristic } & \multirow{2}{*}{$\begin{array}{l}\text { DRM 5.0 } \\
\text { Baseline }\end{array}$} & \multirow{2}{*}{$\begin{array}{c}\text { SNRE } \\
\text { Baseline }\end{array}$} & \multicolumn{2}{|c|}{ Axial Growth Option } & \multicolumn{2}{|c|}{ Radial Growth Option } \\
\hline & & & Nominal & Enhanced & Nominal & Enhanced \\
\hline \multicolumn{7}{|l|}{ Engine System } \\
\hline Thrust (kN) & 111.2 & 72.95 & 111.6 & 111.6 & 111.6 & 111.6 \\
\hline Chamber Inlet Temperature (K) & $\sim 2650-2700$ & 2695 & 2790 & 2940 & 2731 & 2807 \\
\hline Chamber Pressure (psia) & 1000 & 450 & 1000 & 1000 & 1000 & 1000 \\
\hline Nozzle Expansion Ratio & 300:1 & 100:1 & $300: 1$ & $300: 1$ & $300: 1$ & $300: 1$ \\
\hline Specific Impulse (s) & $\sim 900-910$ & 875 & 906 & 941 & 894 & 913 \\
\hline Engine Thrust-to-Weight & 3.43 & 2.92 & 3.49 & 3.50 & 3.59 & 3.60 \\
\hline \multicolumn{7}{|l|}{ Reactor } \\
\hline Active Fuel Length (cm) & & 89.0 & 132.0 & 132.0 & 89.0 & 89.0 \\
\hline Effective Core Radius (cm) & & 29.5 & 29.5 & 29.5 & 35.2 & 35.2 \\
\hline Engine Radius (cm) & & 49.3 & 49.3 & 49.3 & 55.0 & 55.0 \\
\hline Element Fuel/Tie Tube Pattern Type & & SNRE & SNRE & SNRE & Sparse & Sparse \\
\hline Number of Fuel Elements & & 564 & 564 & 564 & 864 & 864 \\
\hline Number of Tie Tube Elements & & 241 & 241 & 241 & 283 & 283 \\
\hline Fuel Fissile Loading $\left(\mathrm{g} \mathrm{U}\right.$ per $\left.\mathrm{cm}^{3}\right)$ & & 0.60 & 0.25 & 0.25 & 0.45 & 0.45 \\
\hline Maximum Enrichment (wt\% U-235) & & 93 & 93 & 93 & 93 & 93 \\
\hline Maximum Fuel Temperature (K) & & 2860 & 2860 & 3010 & 2860 & 2930 \\
\hline Margin to Fuel Melt (K) & & 40 & 190 & 40 & 110 & 40 \\
\hline${ }^{235} \mathrm{U}$ mass $(\mathrm{kg})$ & & 59.6 & 36.8 & 36.8 & 68.5 & 68.5 \\
\hline
\end{tabular}

All four engine options meet the $111.2 \mathrm{kN}\left(25,000-\mathrm{lb}_{\mathrm{f}}\right)$ thrust goal. The axial growth version operating with a maximum fuel temperature constrained to $3010 \mathrm{~K}$ delivers $111.6 \mathrm{kN}$ of thrust with an Isp of 941 seconds at an engine thrust-to-weight of 3.50. The radial growth version operating with a maximum fuel temperature constrained to $2930 \mathrm{~K}$ produces $111.6 \mathrm{kN}$ of thrust with an Isp of 913 seconds at an engine thrust-to-weight of 3.60 .

These designs are certainly not yet optimized and additional performance improvements are a reasonable expectation. For the four engine options, the highest specific impulse is predicted for the axial growth case at enhanced operating conditions. A fraction of a centimeter increase in the radial reflector outer radius would enable use of fuel with a uranium loading of $0.20 \mathrm{~g} / \mathrm{cm}^{3}$ and enable a slightly higher maximum fuel temperature. Improved system level engine performance has not been evaluated using NESS, but an Isp increase of $\sim 7$ seconds is expected.

\subsection{Extension of the SNRE Design to Lower Thrust Systems}

As stated earlier, moderately lower thrust engines may also have important roles. Robotic science missions could benefit directly from smaller nuclear engines, even when NTP is not considered enabling for the particular mission or class of missions. Smaller nuclear engines are also more attractive for an inspace nuclear propulsion technology demonstrator prior to larger scale use for cargo and crewed exploration missions. The lower thrust engine designs could then be used to demonstrate critical technologies that are directly extensible to higher thrust levels. For graphite based engines and in the ideal case, the hexagonal fuel elements and the hexagonal tie tube elements employed in the $\sim 73 \mathrm{kN}$ SNRE, the $111 \mathrm{kN}$ engine, and in the lower thrust engine designs would be identical. At the minimum, the cross-sections for the two element types should be identical and critical performance parameters such as maximum fuel temperature should be identical or conservatively higher in the demonstrator. Material compositions should be identical or similar and demonstrated to be conservative. For example, different ${ }^{235} \mathrm{U}$ enrichments might be used at identical or similar total uranium content in the fuel matrix. Different length elements for the different thrust level engines could still be considered. 
The SNRE contained 564 hexagonal fuel elements and was designed to operate at 367 MWth producing $73.0 \mathrm{kN}$ thrust. Simple power scaling indicates an operating power of $110 \mathrm{MW}$ th for a $22.2 \mathrm{kN}$ $\left(5,000-\mathrm{lb}_{\mathrm{f}}\right)$ engine design. Assuming comparable fuel element performance could be obtained, simple scaling also indicates 175 fuel elements would provide adequate thermal energy for a $22.2 \mathrm{kN}$ thrust design. Core reactivity considerations are much more constraining in small engine designs. Some improvements in the SNRE design could result in a lower number of fuel elements and possibly in a smaller engine. However, it does not appear feasible to obtain adequate reactivity in a practical engine design using only 175 fuel elements in the SNRE configuration and using the SNRE tie tube design.

In NERVA-derived engine designs, the reactor cores are made up of hexagonal fuel elements and hexagonal structural (tie tube) elements. The regeneratively cooled tie tube elements provide structural support for the fuel elements, provide a source of energy to drive the turbomachinery, and incorporate a moderator sleeve to raise neutronic reactivity. Corner elements are removed and complete and partial hexagonal "filler" elements are utilized to complete an approximately cylindrical core.

Two different fuel element and tie tube element patterns have been employed in previous engine designs. Both element types are $1.905 \mathrm{~cm}(0.75 \mathrm{in})$ across the hexagonal element flats. The pattern typically used in larger engine designs and identified here as the "sparse" element pattern (Figure 3) results in a fuel element to tie tube element ratio of about 3 to 1 . The pattern employed in the SNRE design results in a fuel element to tie tube element ratio of about 2 to 1 (Figure 4). Additional reactivity gains may be possible by employing an entirely new pattern identified here as the "dense" element pattern resulting in a fuel element to tie tube element ratio of about 1 to 1 (Figure 5).

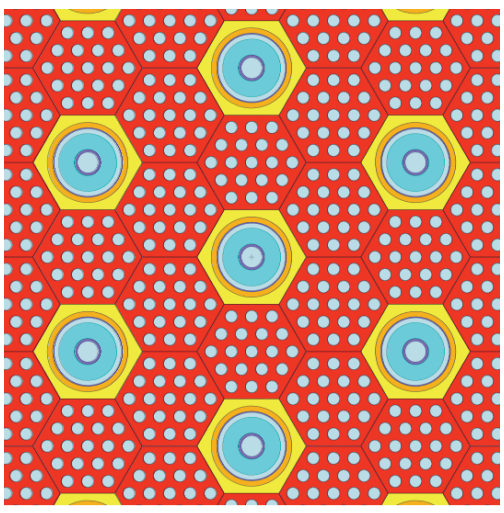

Figure 3. Sparse fuel element and tie tube element pattern.

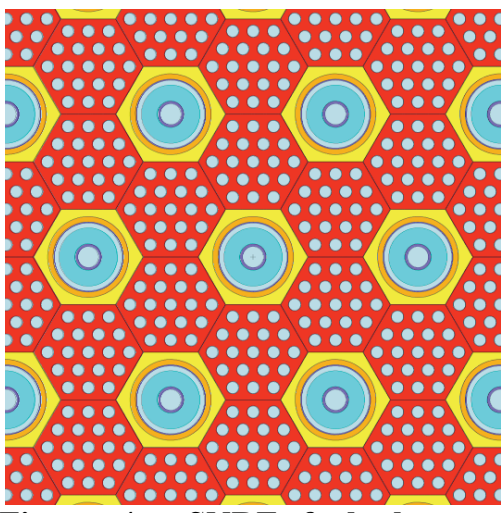

Figure 4. SNRE fuel element and tie tube element pattern.

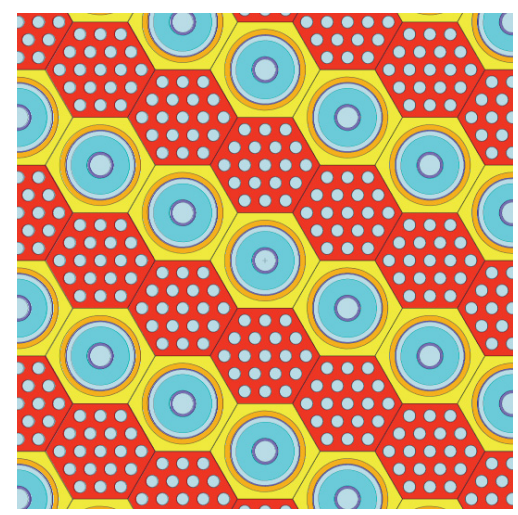

Figure 5. Dense fuel element and tie tube element pattern.

Initial feasibility evaluations were first performed to assess the magnitude of core reactivity changes resulting from simply using the three different fuel element and tie tube patterns in an otherwise identical engine model. The MCNP Monte Carlo transport code and an existing model ${ }^{19}$ of the SNRE engine were utilized. Components outside the active core region remain common to the SNRE, the $111.2 \mathrm{kN}$, and the lower thrust designs. All SNRE radial component thicknesses are preserved except for the beryllium reflector thickness. The geometry and dimensions of the twelve control cylinders are also maintained except for the absorber plate thickness. Beryllium reflector thickness is variable and adjusted as needed in the designs to maintain adequate engine reactivity. Absorber plate thickness is variable and adjusted as needed to maintain adequate reactivity control swing.

Recognizing the constraining core reactivity considerations in small engine designs encouraged immediate incorporation of two readily available methods of reactivity enhancement that had been identified in the $111.2 \mathrm{kN}$ class engine studies. These are changes in the tie tube $\mathrm{ZrH}$ internal moderator geometry (from 1.1684-cm OD to 1.2141-cm OD) and changes in the control drum absorber thickness. 
Parameters for several lower thrust configurations are shown in Table 2 along with data for the SNRE and one of the $111.2 \mathrm{kN}\left(25,000-\mathrm{lb}_{\mathrm{f}}\right)$ engines. Overall engine diameter is shown in the fifth column. The 13 hexagonal row configuration is slightly smaller than the SNRE. The diameter of the 14 hexagonal row configuration is $10.8 \mathrm{~cm}$ smaller than the SNRE. Because of the reflector thickness needed for criticality, the 12 hexagonal row configuration is almost as large as the $111.2 \mathrm{kN}$ engine. Relative sizes are illustrated in Figure 6 for the three lower thrust engine configurations.

Full swing control drum worths are shown in the last column of Table 2. A full swing worth of $\sim 8.9$ dollars had been judged adequate ${ }^{17,18}$ for the SNRE. All three low thrust configurations either have adequate control swing or adequate reactivity margin to support small changes in the drum design to achieve adequate control swing.

Table 2. Reactor parameters for several engine configurations based on the SNRE design.

\begin{tabular}{|c|c|c|c|c|c|c|}
\hline Configuration & $\begin{array}{l}\text { Number of } \\
\text { Fuel } \\
\text { Elements }\end{array}$ & $\begin{array}{l}\text { Number of } \\
\text { Tie Tube } \\
\text { Elements }\end{array}$ & $\begin{array}{c}\text { Reflector } \\
\text { Thickness } \\
(\mathrm{cm})\end{array}$ & $\begin{array}{l}\text { Engine } \\
\text { Diameter } \\
(\mathrm{cm})\end{array}$ & $\begin{array}{c}\text { Hf Absorper } \\
\text { Thickness } \\
(\mathrm{cm})\end{array}$ & $\begin{array}{c}\text { Full Swing } \\
\text { Drum Worth } \\
(\$)\end{array}$ \\
\hline SNRE & 564 & 241 & 14.7 & 98.5 & 0.190 & $\sim 11.2$ \\
\hline $111.2 \mathrm{kN}$ & 864 & 283 & 14.7 & 110.0 & 0.190 & $\sim 9.1$ \\
\hline 14 Hex Row & 260 & 251 & 14.7 & 87.7 & 0.190 & $\sim 10.3$ \\
\hline 14 Hex Row & 260 & 251 & 14.7 & 87.7 & 0.635 & $\sim 11.7$ \\
\hline 13 Hex Row & 216 & 217 & 21.6 & 97.6 & 0.190 & $\sim 8.7$ \\
\hline 13 Hex Row & 216 & 217 & 21.6 & 97.6 & 0.635 & $\sim 9.6$ \\
\hline 12 Hex Row & 184 & 177 & 27.9 & 106.5 & 0.190 & $\sim 7.8$ \\
\hline 12 Hex Row & 184 & 177 & 27.9 & 106.5 & 0.635 & $\sim 8.3$ \\
\hline
\end{tabular}

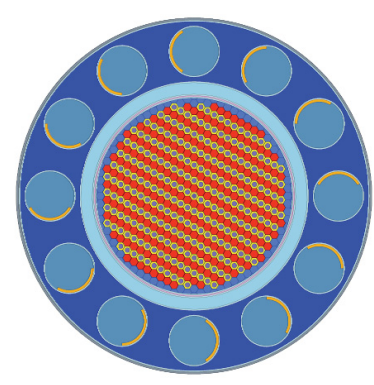

(a) 14 Hexagonal Rows

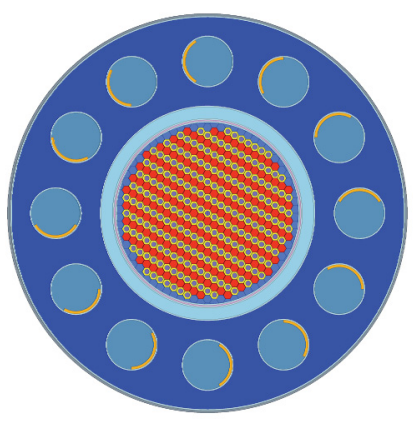

(b) 13 Hexagonal Rows

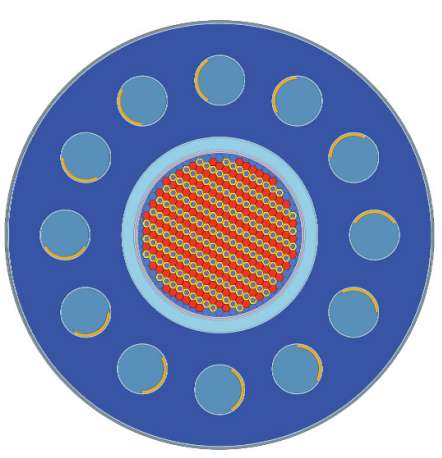

(c) 12 Hexagonal Rows

Figure 6. Cross sections near core mid-plane for three lower thrust engines based on the SNRE design (same scale for all three concepts). 


\subsubsection{System Level Analyses}

Engine performance was evaluated by NASA Glenn using the Nuclear Engine System Simulation (NESS) code. $^{23}$ The NESS code contains an option to calculate a suitable fuel element propellant orificing pattern to minimize fuel element temperature peaking, maintain the peak fuel temperature below a specified limit, and maximize the mixed mean propellant exit temperature. Performance characteristics are shown in Table 3 for the three lower thrust engine options evaluated. A maximum fuel temperature of $2860 \mathrm{~K}$, a chamber pressure of $1000 \mathrm{psia}$, and a nozzle expansion ratio of 300:1 are common for the three options and yield approximately the same calculated chamber inlet temperature and specific impulse. Engine thrust levels range from $33.0 \mathrm{kN}\left(7,420 \mathrm{lb}_{\mathrm{f}}\right)$ to $23.6 \mathrm{kN}\left(5,300 \mathrm{lb}_{\mathrm{f}}\right)$ with engine thrust-to-weight ranging from 1.87 to 1.10 .

Data for the SNRE and from one of the earlier $111.2 \mathrm{kN}\left(25,000-1 b_{f}\right)$ thrust engine options are included for comparison. Engine thrust-to-weight values for the SNRE and the $111.2 \mathrm{kN}$ engine differ slightly from the values shown in Table 1. Differences are due primarily to improved mass estimates for some non-reactor engine components such as piping and to reducing the number of engine gimbals from three to one.

\subsubsection{Results Summary}

Lower thrust engine options based on the Small Nuclear Rocket Engine design are possible using an entirely new hexagonal element pattern resulting in a fuel element to tie tube element ratio of about 1 to 1 . Fuel performance and engine specific impulse comparable to the SNRE and the $111.1 \mathrm{kN}\left(25,000-\mathrm{lb}_{\mathrm{f}}\right)$ class engines may be achieved in engine designs with thrust levels as low as $22.2 \mathrm{kN}\left(5,000 \mathrm{lb}_{\mathrm{f}}\right)$, but the lower thrust designs require relatively thick reflectors to maintain a critical configuration and have low thrust-to-weight.

A design capable of providing a thrust level of $33.0 \mathrm{kN}\left(7,420 \mathrm{lb}_{\mathrm{f}}\right)$ is more practical. The engine thrust-to-weight is only about 1.87 , but this lower thrust engine design could be used to demonstrate critical technologies that are directly extensible to higher thrust levels. Except for the fissile loading, the fuel elements and tie tube elements are exactly as those used in the $111.2 \mathrm{kN}\left(25,000-\mathrm{lb}_{\mathrm{f}}\right)$ design.

The design is not optimized and some performance improvement may be possible. In particular, increasing the active fuel length slightly may allow a thinner reflector and reduce overall engine mass. 
Table 3. Performance characteristics of lower thrust engine designs based on the SNRE.

\begin{tabular}{|c|c|c|c|c|c|}
\hline Performance Characteristic & $\begin{array}{c}111.2 \mathrm{kN} \\
\text { Option }\end{array}$ & $\begin{array}{c}\text { SNRE } \\
\text { Baseline }\end{array}$ & $\begin{array}{c}14 \text { Hex Row } \\
\text { Option }\end{array}$ & $\begin{array}{l}13 \text { Hex Row } \\
\text { Option }\end{array}$ & $\begin{array}{c}12 \text { Hex Row } \\
\text { Option }\end{array}$ \\
\hline \multicolumn{6}{|l|}{ Reactor } \\
\hline Active Fuel Length (cm) & 89.0 & 89.0 & 89.0 & 89.0 & 89.0 \\
\hline Reflector Thickness (cm) & 14.7 & 14.7 & 14.7 & 21.6 & 27.9 \\
\hline Engine Diameter $(\mathrm{cm})$ & 110.0 & 98.5 & 87.7 & 97.6 & 106.5 \\
\hline Element Pattern Type & Sparse & SNRE & Dense & Dense & Dense \\
\hline Number of Fuel Elements & 864 & 564 & 260 & 216 & 184 \\
\hline Number of Tie Tube Elements & 283 & 241 & 251 & 217 & 177 \\
\hline Fuel Fissile Loading $\left(\mathrm{g} \mathrm{U} / \mathrm{cm}^{3}\right)$ & 0.45 & 0.60 & 0.60 & 0.60 & 0.60 \\
\hline Maximum Fuel Temperature (K) & 2860 & 2860 & 2860 & 2860 & 2860 \\
\hline Margin to Fuel Melt (K) & 110 & 40 & 40 & 40 & 40 \\
\hline${ }^{235} \mathrm{U}$ Mass (kg) & 68.5 & 59.6 & 27.5 & 22.8 & 19.4 \\
\hline \multicolumn{6}{|l|}{ Component Masses } \\
\hline Reactor (kg) & 2343 & 1901 & 1432 & 1592 & 1892 \\
\hline Pressure Vessel (kg) & 303 & 149 & 244 & 225 & 212 \\
\hline Nozzle (kg) & 151 & 151 & 53 & 45 & 39 \\
\hline Turbomachinery \& Piping (kg) & 112 & 85 & 41 & 34 & 30 \\
\hline Gimbal (kg) & 60 & 43 & 26 & 14 & 13 \\
\hline Engine Total $(\mathrm{kg})$ & 2969 & 2328 & 1797 & 1910 & 2186 \\
\hline Engine Total $\left(\mathrm{lb}_{\mathrm{m}}\right)$ & 6546 & 5133 & 3961 & 4210 & 4820 \\
\hline \multicolumn{6}{|l|}{ Engine System } \\
\hline Thrust $(\mathrm{kN})$ & 111.7 & 73.0 & 33.0 & 26.7 & 23.6 \\
\hline Thrust $\left(\mathrm{klb}_{\mathrm{f}}\right)$ & 25.1 & 16.4 & 7.42 & 6.00 & 5.30 \\
\hline Chamber Inlet Temperature (K) & 2731 & 2695 & 2736 & 2738 & 2734 \\
\hline Chamber Pressure (MPa) & 6.89 & 3.10 & 6.89 & 6.89 & 6.89 \\
\hline Chamber Pressure (psia) & 1000 & 450 & 1000 & 1000 & 1000 \\
\hline Nozzle Expansion Ratio & $300: 1$ & 100:1 & $300: 1$ & $300: 1$ & $300: 1$ \\
\hline Specific Impulse (s) & 894 & 875 & 894 & 894 & 893 \\
\hline Engine Thrust-to-Weight & 3.82 & 3.20 & 1.87 & 1.43 & 1.10 \\
\hline
\end{tabular}




\section{Fast Spectrum Systems}

The GE- $710^{4}$ and $\mathrm{ANL}^{5}$ nuclear rocket programs focused on refractory metal alloy fuels for both power and propulsion concepts. Both programs had been established as backups to the primary Rover/NERVA using graphite based fuels. The choice of refractory metal alloy fuels as the secondary fuel type had been based on a combination of the greater experience base, lower thermal neutron absorption cross-section, and ease of fabrication for the graphite fuels.

The 710 Program had been initiated in 1962 with the direction to conduct reactor tests demonstrating performance for both closed loop systems using neon as the coolant and open loop systems using hydrogen as the coolant. Program direction was changed in 1963, 1965, and 1966 prior to termination in 1968. The open loop direct propulsion test was dropped with the 1963 direction.

Two reference engine designs were developed during the ANL program. The primary was a $2000 \mathrm{MW}$ th engine yielding $489.7 \mathrm{kN}\left(110,100 \mathrm{lb}_{\mathrm{f}}\right)$ thrust with a specific impulse of 832 seconds. The engine operated on a topping cycle. The second reference design developed $46.8 \mathrm{kN}\left(10,530 \mathrm{lb}_{\mathrm{f}}\right)$ thrust with a specific impulse of 821 seconds. This engine operated on a hot bleed cycle. A nozzle expansion ratio of 50:1 was used for both designs.

Fast spectrum reactor systems have been revisited since the 1973 program terminations. In particular, Argonne National Laboratory and General Electric collaborated on a study ${ }^{25}$ funded by the Air Force Astronautics Laboratory to evaluate fast spectrum reactors for direct nuclear thermal propulsion. Pratt \& Whitney has proposed the XNR2 $2000^{26}$ as a near term fast spectrum reactor concept for direct nuclear thermal propulsion as well as the ESCORT ${ }^{27}$ bimodal and TRITON ${ }^{28}$ trimodal concepts.

Advertized advantages of fast spectrum systems include the potential for better fission product retention, long operating life with multiple restarts and temperature cycling, and an intrinsic "neutronic spectral shift" safety feature that helps maintain reactor subcriticality in the event of a water immersion accident. Fast spectrum reactors also tend to be much more compact than thermal spectrum systems, although that does not automatically translate to lower mass systems with higher thrust-to-weight. The inherently higher fissile mass of a fast spectrum system is an important disadvantage.

\subsection{Cermet Nuclear Fuels}

\subsubsection{Fuel Compositions}

Haertling and Hanrahan ${ }^{29}$ have summarized refractory metal alloy fuels development for propulsion engines. Bhattacharyya ${ }^{6}$ has also summarized refractory metal alloy and other fuels suitable for nuclear thermal propulsion. The ceramic-metallic "cermet" fuels contain $\mathrm{UO}_{2}$ or $\mathrm{UN}$ in a refractory metal matrix. The UN fuels were primarily considered for applications with operating temperature lower than those desired for nuclear thermal propulsion. Refractory metals suitable for the very high temperatures desired are tungsten, molybdenum, tantalum, rhenium and their alloys. Spherical particles of $\mathrm{UO}_{2}$ are usually employed and the particle may be bare or coated. Tungsten is the coating of choice, especially for fuels using tungsten or tungsten alloys as the metal matrix. Particle size is an important variable and one or multiple sizes may be used. Oxygen stabilizers may be added to the fuel particle and to the metal matrix. The stabilizer of choice was $\mathrm{ThO}_{2}$ for the 710 Program and $\mathrm{Gd}_{2} \mathrm{O}_{3}$ for the ANL Program. Fuel loadings of up to $60 \% \mathrm{UO}_{2}$ (by volume) in the metal matrix were assumed for both GE-710 and ANL engine designs. The $\mathrm{W}-\mathrm{UO}_{2}$ cermet density or fraction of theoretical density is also an important variable. 


\subsubsection{Clad Compositions}

Several materials have been evaluated for the cladding on the propellant channels and on the exterior surfaces of the hexagonal fuel elements. The 710 Program tested tantalum, the tantalum alloys Ta-10W and Ta-8W-2Hf (T-111), Mo-50Re, W-25Re-30Mo, W-30Re-30Mo. The W-30Re-30Mo (by atom percent) alloy was the preferred clad for direct propulsion designs at the close of the program. The ANL designs used tungsten for the coolant channel clad and W-25Re for the exterior clad. The alloy is listed as both W-Re and W-25\% Re in multiple places in Reference 5. For the $2000 \mathrm{MW}$ th engine the material is listed as W-25 wt\% Re and for the $200 \mathrm{MW}$ th engine it is listed as W-25Re by volume.

\subsubsection{Fuel Element Geometry}

Numerous hexagonal fuel element geometries have been considered for fast spectrum reactor power and propulsion concepts. Data for several elements proposed for propulsion engine designs are summarized in Table 4. In addition to the GE-710 and ANL heritage designs, data for four industry proposed concepts are listed. The heritage NERVA element geometry data for graphite fuel based thermal spectrum engine designs are included for comparison. The data are also shown in Table 5 using traditional units.

Table 4: Hexagonal fuel element geometry data for proposed propulsion engine concepts.

\begin{tabular}{|c|c|c|c|c|c|c|c|c|}
\hline $\begin{array}{l}\text { Element } \\
\text { Type }\end{array}$ & $\begin{array}{l}\text { Exterior } \\
\text { Width } \\
(\mathrm{cm})\end{array}$ & $\begin{array}{l}\text { Exterior } \\
\text { Clad } \\
(\mathrm{cm})\end{array}$ & $\begin{array}{l}\text { Number } \\
\text { of } \\
\text { Channels }\end{array}$ & $\begin{array}{l}\text { Channel } \\
\text { Pitch } \\
\text { (cm) }\end{array}$ & $\begin{array}{c}\text { Matrix } \\
\text { Borehole } \\
\text { Diameter } \\
(\mathrm{cm})\end{array}$ & $\begin{array}{l}\text { Borehole } \\
\text { Clad } \\
(\mathrm{cm})\end{array}$ & $\begin{array}{c}\text { Hydrogen } \\
\text { Passage } \\
\text { Diameter } \\
(\mathrm{cm})\end{array}$ & $\begin{array}{l}\text { Matrix } \\
\text { Web } \\
(\mathrm{cm})\end{array}$ \\
\hline \multicolumn{9}{|c|}{ Heritage Cermet (ANL) } \\
\hline ANL-200 & 2.7737 & 0.01778 & 61 & 0.34544 & 0.20574 & 0.01778 & 0.17018 & 0.13970 \\
\hline ANL-2000 & 4.9022 & 0.07620 & 331 & 0.25908 & 0.20574 & 0.01778 & 0.17018 & 0.05334 \\
\hline \multicolumn{9}{|c|}{ Heritage Cermet (GE-710) } \\
\hline GE-710 & 2.3561 & 0.03810 & 91 & 0.23825 & 0.13208 & 0.02032 & 0.09144 & 0.10668 \\
\hline \multicolumn{9}{|c|}{ Pratt \& Whitney Cermet } \\
\hline XNR-2000-A & 3.5560 & 0.05080 & 169 & 0.25908 & 0.20320 & 0.01778 & 0.16764 & 0.05588 \\
\hline XNR-2000-B & 3.5560 & 0.05080 & 37 & 0.54610 & 0.39116 & 0.01778 & 0.35560 & 0.15494 \\
\hline \multicolumn{9}{|l|}{ Proprietary } \\
\hline ESCORT & 4.3180 & 0.10160 & 48 & $\sim 0.5715$ & 0.28956 & 0.01778 & 0.25400 & $\sim 0.2819$ \\
\hline \multicolumn{9}{|c|}{ Heritage NERVA Geometry } \\
\hline NE-X & 1.9050 & 0.00508 & 19 & 0.40894 & 0.25654 & 0.01016 & 0.23622 & 0.15240 \\
\hline
\end{tabular}


Table 5: Hexagonal fuel element geometry data in traditional engineering units for proposed propulsion engine concepts.

\begin{tabular}{|c|c|c|c|c|c|c|c|c|}
\hline $\begin{array}{l}\text { Element } \\
\text { Type }\end{array}$ & $\begin{array}{l}\text { Exterior } \\
\text { Width } \\
\text { (Inches) }\end{array}$ & $\begin{array}{l}\text { Exterior } \\
\text { Clad } \\
\text { (Inches) }\end{array}$ & $\begin{array}{l}\text { Number } \\
\text { of } \\
\text { Channels }\end{array}$ & $\begin{array}{l}\text { Channel } \\
\text { Pitch } \\
\text { (Inches) }\end{array}$ & $\begin{array}{l}\text { Matrix } \\
\text { Borehole } \\
\text { Diameter } \\
\text { (Inches) }\end{array}$ & $\begin{array}{c}\text { Borehole } \\
\text { Clad } \\
\text { (Inches) }\end{array}$ & $\begin{array}{l}\text { Hydrogen } \\
\text { Passage } \\
\text { Diameter } \\
\text { (Inches) }\end{array}$ & $\begin{array}{l}\text { Matrix } \\
\text { Web } \\
\text { (Inches) }\end{array}$ \\
\hline \multicolumn{9}{|c|}{ Heritage Cermet (ANL) } \\
\hline ANL-200 & 1.092 & 0.007 & 61 & 0.136 & 0.081 & 0.007 & 0.067 & 0.055 \\
\hline ANL-2000 & 1.930 & 0.030 & 331 & 0.102 & 0.081 & 0.007 & 0.067 & 0.021 \\
\hline \multicolumn{9}{|c|}{ Heritage Cermet (GE-710) } \\
\hline GE-710 & 0.9276 & 0.015 & 91 & 0.0938 & 0.052 & 0.008 & 0.036 & 0.042 \\
\hline \multicolumn{9}{|c|}{ Pratt \& Whitnev Cermet } \\
\hline XNR-2000-A & 1.40 & 0.020 & 169 & 0.102 & 0.080 & 0.007 & 0.066 & 0.022 \\
\hline XNR-2000-B & 1.40 & 0.020 & 37 & 0.215 & 0.154 & 0.007 & 0.140 & 0.061 \\
\hline \multicolumn{9}{|l|}{ Proprietary } \\
\hline ESCORT & 1.70 & 0.040 & 48 & $\sim 0.225$ & 0.114 & 0.007 & 0.100 & $\sim 0.111$ \\
\hline \multicolumn{9}{|c|}{ Heritage NERVA Geometry } \\
\hline NE-X & 0.750 & 0.002 & 19 & 0.161 & 0.101 & 0.004 & 0.093 & 0.060 \\
\hline
\end{tabular}

\subsection{Fast Spectrum Reactor Configurations}

In addition to the considerable range of fuel compositions and hexagonal fuel element types described in the previous section, a large number of different core arrangements have been proposed. Common features include the use of both radial and axial reflectors. Beryllium, beryllium oxide $(\mathrm{BeO})$, and the heavy metals nickel and molybdenum have been evaluated. Beryllium is usually employed for the radial reflector. Axial reflectors are usually included only at the cooler forward end of the reactor core and $\mathrm{BeO}$ is commonly used.

Reactivity control is usually provided by cylindrical control drums located in the radial reflector. The rotating drums contain neutron absorbers over only a portion or sector of the drum. Boron carbide, usually enriched in the ${ }^{10} \mathrm{~B}$ isotope, is the most common absorber material. Hafnium and europium, as $\mathrm{EuO}_{2}-\mathrm{Al}$, are often used in the more thermal spectrum designs but are sometimes also used for the fast spectrum designs. Sometimes moveable reflector sections are employed instead of control drums. 


\subsubsection{Design and Analysis Methods}

The analysis approach is as summarized in Section 2 and includes evaluation of reactor neutronic performance, evaluation of the combined thermal-fluid-structural performance of the fuel element, and evaluation of engine system level performance. An effective design and analysis sequence is to first establish a preliminary core configuration that meets the fundamental neutronic performance requirements of criticality and adequate control swing. Results from neutronic analyses of the reactor core can then be utilized to provide neutron and gamma energy deposition rates as input to integrated thermal-fluid-structural analyses of the core interior components. Once acceptable neutronic and thermal performance is achieved, overall engine system performance can be evaluated. The above sequence is typically an iterative process.

There is current interest in both $111.2 \mathrm{kN}\left(25,000-\mathrm{lb}_{\mathrm{f}}\right)$ class designs and in lower thrust designs demonstrating technologies that are directly extensible to the higher thrust level. As with the thermal neutron spectrum engines, core reactivity considerations will be more constraining in the lower thrust systems. Lower thrust systems may be characterized as criticality limited. The approach taken here is to first focus on selected lower thrust designs using the fuel types identified in Table 4. Higher thrust versions of any or all of the lower thrust designs can then be evaluated. In all cases, the growth versions utilize the same hexagonal fuel element type as the lower thrust counterpart. The process is illustrated below.

The iterative steps are:

(a) Select a fuel type and establish an initial core configuration based on criticality and control swing

(b) Estimate approximate thrust level based on power density considerations for that particular fuel

(c) Modify core configuration to adjust criticality, control swing, and estimated thrust level

(d) Evaluate combined thermal-fluid-structural performance of element (NASA GRC)

(e) Evaluate system level performance (NASA GRC)

(f) Establish initial higher thrust core configurations using the same fuel types as in Step (a)

(g) Modify core configuration to adjust criticality, control swing, and estimated thrust level

(h) Evaluate combined thermal-fluid-structural performance of element (NASA GRC)

(i) Evaluate system level performance (NASA GRC)

(j) Optimize both lower and higher thrust designs

\subsubsection{Initial Configurations}

As noted above, past engine designs have incorporated a variety of fuel and clad compositions, fuel element designs, radial and axial reflector configurations, and reactivity control methods. In order to compare fuel element performance on a more consistent basis, a common core layout was adopted for the initial evaluations.

Beryllium at $90 \%$ theoretical density was assumed for the radial reflector. Based on past designs, the reduced density is conservative for reactivity evaluations while allowing $10 \%$ void space to later incorporate cooling channels for thermal management. Three different reflector thicknesses of $10 \mathrm{~cm}$, $15 \mathrm{~cm}$, and $20 \mathrm{~cm}$ were considered.

The availability of adequate control swing was estimated using annular zones of absorber material in the reflector to simulate control drums. The relative worths of hafnium, $\mathrm{EuO}_{2}-\mathrm{Al}$, and $\mathrm{B}_{4} \mathrm{C}-\mathrm{Al}$ were compared in several configurations. The performance of hafnium and europium was comparable but 
inferior to $\mathrm{B}_{4} \mathrm{C}-\mathrm{Al}$. An annular zone at the middle of the reflector was assumed in order to confirm adequate core reactivity with the presence of absorbers in the reflector. Annular zones near the inner and outer radial reflector surfaces were used to estimate available control swing.

\subsection{Neutronics Results for Criticality Limited Fast Spectrum Reactor Configurations}

Reactor cores made up of the element types shown in Table 4 are being evaluated. A total fuel element length of $78.74 \mathrm{~cm}(31.00 \mathrm{in})$ is assumed for the initial configurations. The active fuel region is $60.96 \mathrm{~cm}(24.00 \mathrm{in})$ with a $2.54 \mathrm{~cm}(1.00 \mathrm{in})$ hydrogen plenum at the hot end and a $15.24 \mathrm{~cm}(6.00 \mathrm{in})$ $\mathrm{BeO}$ axial reflector at the cooler forward end of the core. The geometry of the $\mathrm{BeO}$ axial extension is assumed to be identical with the fuel matrix geometry including number of coolant channels, coolant channel clad thickness and composition, and external clad composition and thickness. The $\mathrm{BeO}$ matrix is assumed to be at $90 \%$ theoretical density.

The fuel composition from the smaller of the two ANL designs is assumed for all evaluations. This composition is, by volume, $60 \% \mathrm{UO}_{2}, 34 \% \mathrm{~W}$, and $6 \% \mathrm{Gd}_{2} \mathrm{O}_{3}$. The fuel matrix is assumed to be at $100 \%$ theoretical density. A constant ${ }^{235} \mathrm{U}$ enrichment of $93 \mathrm{wt} \%$ is assumed. Element exterior clad and borehole clad is assumed to be W-25Re by volume.

Potential core configurations are defined by adjusting both the bounding core radius and the number of fuel elements to fit within that radius while achieving a critical configuration with one or more of the three reflector thicknesses considered. Partial hexagonal elements are used as fillers to complete the cylindrical core geometry. The partial filler elements are assumed to be tungsten at $80 \%$ theoretical density. Based on past designs, the reduced density is conservative for reactivity evaluations while allowing 20\% void space to later incorporate cooling channels for thermal management.

The resulting configurations are simply critical or near critical. The achievable operating powers and resulting thrust levels have not yet been evaluated. The critical configurations are not yet optimized for either lower thrust or higher thrust engines.

Calculated control swing worths shown in the following tables are based on simple but conservative approximate models and must be confirmed by explicitly modeling the control drums. For the reference designs developed during the ANL program, a control swing of 3-5\$ was considered acceptable if a reactivity shimming capability of $\pm 4 \$$ were available.

Both core masses and ${ }^{235} \mathrm{U}$ content for the cores are included in the following tables. Both core mass and ${ }^{235} \mathrm{U}$ content will change as the cores are optimized for either lower thrust or higher thrust engines.

Results for the configurations evaluated to date are shown in the following sections.

\subsubsection{Configurations Based on ANL Heritage Cermet Designs}

Characteristics of selected configurations with cores made up of the two ANL heritage cermet fuel element types are shown in Table 6. Although the dimensions and mass values will change as the configurations are optimized, several trends are apparent. The ANL-200 element from a lower thrust engine design with lower thermal power yields a more compact core with lower core mass and ${ }^{235} \mathrm{U}$ content. This configuration is adequate from criticality and control swing considerations, but the maximum power density and resulting thrust level have not yet been evaluated. The ANL-2000 element was designed to support operation at a much higher power density. Higher power density forces increased coolant volume fraction and decreased fuel matrix volume fraction in the element and reactor core. The combination yields a significantly larger core with higher core mass and ${ }^{235} \mathrm{U}$ content. 
Available control swing appears adequate. Calculated control swing for the larger core with a thin radial reflector is marginal at $\sim 2.5 \$$. Even if the low value persists when control drums are explicitly modeled, small changes to optimize the configuration will raise the calculated control swing worth.

Table 6: Characteristics of selected reactor configurations based on ANL heritage cermet fuel designs.

\begin{tabular}{|c|c|c|c|c|c|c|c|c|}
\hline $\begin{array}{l}\text { Element } \\
\text { Type }\end{array}$ & $\begin{array}{l}\text { Core } \\
\text { Radius } \\
(\mathrm{cm})\end{array}$ & $\begin{array}{l}\text { Number } \\
\text { Of Hex } \\
\text { Elements }\end{array}$ & $\begin{array}{c}\text { Radial } \\
\text { Reflector } \\
\text { Thickness } \\
\text { (cm }\end{array}$ & $\begin{array}{l}\text { Reflector } \\
\text { Outer } \\
\text { Radius } \\
(\mathrm{cm})\end{array}$ & $\begin{array}{l}\text { Calculated } \\
\text { k-effective }\end{array}$ & $\begin{array}{l}\text { Control } \\
\text { Worth } \\
(\$)\end{array}$ & $\begin{array}{l}\text { Core } \\
\text { Mass } \\
(\mathrm{kg})\end{array}$ & $\begin{array}{l}{ }^{235} \mathrm{U} \\
\text { Mass } \\
(\mathrm{kg})\end{array}$ \\
\hline \multicolumn{9}{|c|}{ 1.092-Inch (2.7737-cm) Exterior Flat-to-Flat Hexagonal Element with 61 Channels } \\
\hline ANL-200 & 17.5 & 121 & 10.0 & 27.5 & 0.9973 & 5.02 & 1000 & 177.3 \\
\hline ANL-200 & 17.5 & 121 & 15.0 & 32.5 & 1.0123 & 6.47 & 1124 & 177.3 \\
\hline ANL-200 & 17.5 & 121 & 20.0 & 37.5 & 1.0195 & 6.89 & 1268 & 177.3 \\
\hline \multicolumn{9}{|c|}{ 1.930-Inch $(4.9022-\mathrm{cm})$ Exterior Flat-to-Flat Hexagonal Element with 331 Channels } \\
\hline ANL-2000 & 37.3 & 187 & 10.0 & 47.3 & 0.9993 & 2.51 & 3738 & 523.7 \\
\hline ANL-2000 & 37.3 & 187 & 15.0 & 52.3 & 1.0069 & 3.44 & 3946 & 523.7 \\
\hline ANL-2000 & 37.3 & 187 & 20.0 & 57.3 & 1.0108 & 3.69 & 4174 & 523.7 \\
\hline
\end{tabular}

\subsubsection{Configurations Based on the GE-710 Heritage Cermet Design}

Characteristics of selected configurations with cores made up of the GE-710 heritage cermet fuel element type are listed in Table 7. The GE-710 element has a fuel matrix volume fraction similar to the ANL-200 element. The number of hexagonal fuel elements needed for a critical configuration is different because of different element sizes. The resulting core radius, core mass, and ${ }^{235} \mathrm{U}$ content are comparable. This configuration is adequate from criticality and control swing considerations, but the maximum power density and resulting thrust level have not yet been evaluated.

Table 7: Characteristics of selected reactor configurations based on the GE-710 heritage cermet fuel design.

\begin{tabular}{|c|c|c|c|c|c|c|c|c|}
\hline $\begin{array}{l}\text { Element } \\
\text { Type }\end{array}$ & $\begin{array}{l}\text { Core } \\
\text { Radius } \\
(\mathrm{cm})\end{array}$ & $\begin{array}{l}\text { Number } \\
\text { Of Hex } \\
\text { Elements }\end{array}$ & $\begin{array}{c}\text { Radial } \\
\text { Reflector } \\
\text { Thickness } \\
\text { (cm }\end{array}$ & $\begin{array}{l}\text { Reflector } \\
\text { Outer } \\
\text { Radius } \\
(\mathrm{cm})\end{array}$ & $\begin{array}{l}\text { Calculated } \\
\text { k-effective }\end{array}$ & $\begin{array}{l}\text { Control } \\
\text { Worth } \\
(\$)\end{array}$ & $\begin{array}{c}\text { Core } \\
\text { Mass } \\
(\mathrm{kg})\end{array}$ & $\begin{array}{c}{ }^{235} \mathrm{U} \\
\text { Mass } \\
(\mathrm{kg})\end{array}$ \\
\hline \multicolumn{9}{|c|}{ 0.9276-Inch (2.3561-cm) Exterior Flat-to-Flat Hexagonal Element with 91 Channels } \\
\hline GE-710 & 18.0 & 169 & 10.0 & 28.0 & 0.9933 & 3.56 & 1171 & 180.5 \\
\hline GE-710 & 18.0 & 169 & 15.0 & 33.0 & 1.0032 & 4.44 & 1297 & 180.5 \\
\hline GE-710 & 18.0 & 169 & 20.0 & 38.0 & 1.0079 & 4.68 & 1444 & 180.5 \\
\hline
\end{tabular}




\subsubsection{Configurations Based on Pratt and Whitney Proposed Cermet Fuel Element Designs}

Characteristics of selected configurations with cores made up of the Pratt and Whitney proposed cermet fuel element types are listed in Table 8 . Both of the 3.556-cm $(1.40$-inch) element types were proposed for a nominal $111.2 \mathrm{kN}\left(25,000-\mathrm{lb}_{\mathrm{f}}\right)$ engine design. The 37 -channel version has a higher fuel matrix volume fraction and yields a smaller configuration than the 169-channel version. The third element type is from a recently proposed design by Pratt \& Whitney Rocketdyne for direct nuclear thermal propulsion. This still proprietary element design was proposed to provide a logical growth path to the bimodal ESCORT and trimodal TRITON designs. With one exception, the configurations are adequate from criticality and control swing considerations. The maximum power densities and resulting thrust levels have not yet been evaluated.

Table 8: Characteristics of selected reactor configurations based on proposed Pratt and Whitney cermet fuel element designs.

\begin{tabular}{|c|c|c|c|c|c|c|c|c|}
\hline $\begin{array}{l}\text { Element } \\
\text { Type }\end{array}$ & $\begin{array}{l}\text { Core } \\
\text { Radius } \\
(\mathrm{cm})\end{array}$ & $\begin{array}{l}\text { Number } \\
\text { Of Hex } \\
\text { Elements }\end{array}$ & $\begin{array}{l}\text { Radial } \\
\text { Reflector } \\
\text { Thickness } \\
(\mathrm{cm})\end{array}$ & $\begin{array}{l}\text { Reflector } \\
\text { Outer } \\
\text { Radius } \\
(\mathrm{cm})\end{array}$ & $\begin{array}{l}\text { Calculated } \\
\text { k-effective }\end{array}$ & $\begin{array}{l}\text { Control } \\
\text { Worth } \\
(\$)\end{array}$ & $\begin{array}{l}\text { Core } \\
\text { Mass } \\
(\mathrm{kg})\end{array}$ & $\begin{array}{c}{ }^{235} \mathrm{U} \\
\text { Mass } \\
(\mathrm{kg})\end{array}$ \\
\hline \multicolumn{9}{|c|}{ 1.40-Inch (3.5560-cm) Exterior Flat-to-Flat Hexagonal Element with 169 Channels } \\
\hline XNR-2000-A & 32.0 & 253 & 10.0 & 42.0 & 0.9915 & 3.05 & 2882 & 403.0 \\
\hline XNR-2000-A & 32.0 & 253 & 15.0 & 47.0 & 1.0004 & 4.10 & 3067 & 403.0 \\
\hline XNR-2000-A & 32.0 & 253 & 20.0 & 52.0 & 1.0048 & 4.35 & 3274 & 403.0 \\
\hline \multicolumn{9}{|c|}{ 1.40-Inch $(3.5560-\mathrm{cm})$ Exterior Flat-to-Flat Hexagonal Element with 37 Channels } \\
\hline XNR-2000-B & 24.0 & 139 & 10.0 & 34.0 & 1.0109 & 3.52 & 1604 & 268.6 \\
\hline XNR-2000-B & 24.0 & 139 & 15.0 & 39.0 & 1.0212 & 4.46 & 1755 & 268.6 \\
\hline XNR-2000-B & 24.0 & 139 & 20.0 & 44.0 & 1.0260 & 4.68 & 1926 & 268.6 \\
\hline \multicolumn{9}{|c|}{ Proprietary Element Design Providing Growth Path to Bimodal and Trimodal Designs (P\&WR) } \\
\hline P\&WR & 20.0 & 61 & 10.0 & 30.0 & 1.0059 & 3.26 & 1296 & 204.5 \\
\hline P\&WR & 20.0 & 61 & 15.0 & 35.0 & 1.0150 & 4.01 & 1430 & 204.5 \\
\hline P\&WR & 20.0 & 61 & 20.0 & 40.0 & 1.0190 & 4.25 & 1585 & 204.5 \\
\hline \multicolumn{9}{|c|}{ 1.70-Inch Exterior Flat-to-Flat Hexagonal Element with 48 Channels } \\
\hline ESCORT & 25.5 & 109 & 10.0 & 35.5 & 1.0066 & 2.66 & 1919 & 295.5 \\
\hline ESCORT & 25.5 & 109 & 15.0 & 40.5 & 1.0142 & 3.36 & 2076 & 295.5 \\
\hline ESCORT & 25.5 & 109 & 20.0 & 45.5 & 1.0178 & 3.56 & 2253 & 295.5 \\
\hline
\end{tabular}




\subsubsection{Configurations Using Cermet Fueled Elements Duplicating the NERVA Hexagonal Element Geometry}

Recent consideration has been given to fabrication of a cermet fueled element similar in geometry to the NERVA hexagonal element. Specific element geometry details for the proposed fabrication are not available. The heritage NERVA geometry was assumed here with cermet fuel substituted for composite fuel and R-25Re clad substituted for $\mathrm{ZrC}$ clad. Clad for cermet and graphite elements served different purposes and simple material substitution is not appropriate for design but is adequate for this comparison. Characteristics of selected configurations are shown in Table 9.

Fuel matrix web thicknesses for this configuration and for the XNR-2000B design are similar but the fuel matrix volume fraction is about $25 \%$ higher in the NE-X geometry and will constrain the NE-X element to a lower operating power. This configuration is adequate from criticality and control swing considerations, but the maximum power density and resulting thrust level have not yet been evaluated.

Table 9: Configurations using cermet fueled elements duplicating the NERVA hexagonal element geometry.

\begin{tabular}{|c|c|c|c|c|c|c|c|c|}
\hline $\begin{array}{l}\text { Element } \\
\text { Type }\end{array}$ & $\begin{array}{l}\text { Core } \\
\text { Radius } \\
(\mathrm{cm})\end{array}$ & $\begin{array}{l}\text { Number } \\
\text { Of Hex } \\
\text { Elements }\end{array}$ & $\begin{array}{c}\text { Radial } \\
\text { Reflector } \\
\text { Thickness } \\
\text { (cm }\end{array}$ & $\begin{array}{l}\text { Reflector } \\
\text { Outer } \\
\text { Radius } \\
(\mathrm{cm})\end{array}$ & $\begin{array}{l}\text { Calculated } \\
\text { k-effective }\end{array}$ & $\begin{array}{c}\text { Control } \\
\text { Worth } \\
\text { (\$) }\end{array}$ & $\begin{array}{l}\text { Core } \\
\text { Mass } \\
(\mathrm{kg})\end{array}$ & $\begin{array}{l}{ }^{235} \mathrm{U} \\
\text { Mass } \\
(\mathrm{kg})\end{array}$ \\
\hline \multicolumn{9}{|c|}{ 0.75-Inch $(1.9050-\mathrm{cm})$ Exterior Flat-to-Flat Hexagonal Element with 19 Channels } \\
\hline NE-X & 17.0 & 256 & 10.0 & 27.0 & 1.0082 & 6.63 & 857 & 178.7 \\
\hline NE-X & 17.0 & 256 & 15.0 & 32.0 & 1.0292 & 8.80 & 979 & 178.7 \\
\hline NE-X & 17.0 & 256 & 20.0 & 37.0 & 1.0397 & 9.46 & 1121 & 178.7 \\
\hline
\end{tabular}

\subsection{Preliminary Estimates of System Level Performance for Criticality Limited Fast Spectrum Configurations}

Results reported in the previous section are from the initial set of performance evaluations. Configurations are critical and appear to have adequate control swing. Fuel element and system level performance are to be evaluated by NASA GRC. Preliminary estimates of allowable core thermal power can be made based on power density considerations and preliminary estimates of engine thrust level can be made by simple thermal power scaling from heritage designs. Results of these preliminary estimates are shown in Table 10.

Four of the eight criticality limited configurations shown in Table 10 may be categorized as smaller and lower thrust systems. Two of the lower power density designs, those based on the ANL-200 and the NE-X, provide comparable thrust levels of $\sim 39.6 \mathrm{kN}\left(\sim 8,900 \mathrm{lb}_{\mathrm{f}}\right)$. The sizes of both designs are criticality limited in their current configuration. As noted in Section 4.2.1, core modifications to be performed in the third step may yield smaller critical designs that would provide lower thrust levels while maintaining the same fuel matrix power densities.

Two of the intermediate power density designs, those based on the GE-710 and XNR-2000-B fuel elements, provide comparable thrust levels slightly below the $111.2 \mathrm{kN}\left(25,000-\mathrm{lb}_{\mathrm{f}}\right)$ class. Minor core modifications during the next step can bring either design to the $111.2 \mathrm{kN}$ thrust level. Engine masses and ${ }^{235} \mathrm{U}$ contents are lower with the GE-710 design but the fuel matrix power density is higher. 
For all designs, integrated thermal-fluid-structural analyses of the fuel elements are critical to confirming or establishing allowable fuel matrix power densities and ultimately engine system performances.

Table 10: Preliminary estimates of system level performance for criticality limited fast spectrum configurations.

\begin{tabular}{|c|c|c|c|c|c|c|}
\hline $\begin{array}{l}\text { Element } \\
\text { Type }\end{array}$ & $\begin{array}{l}\text { Core } \\
\text { Radius } \\
(\mathrm{cm})\end{array}$ & $\begin{array}{l}\text { Active } \\
\text { Fuel } \\
\text { Length } \\
(\mathrm{cm})\end{array}$ & $\begin{array}{l}\text { Number } \\
\text { Of Hex } \\
\text { Elements }\end{array}$ & $\begin{array}{l}\text { Heritage or Proposed } \\
\text { Design Power Density } \\
\text { In Fuel Matrix } \\
\text { (MW/liter) }\end{array}$ & $\begin{array}{l}\text { Projected } \\
\text { Core } \\
\text { Power } \\
\text { (MWth) }\end{array}$ & $\begin{array}{c}\text { Projected } \\
\text { Approximate } \\
\text { Engine Thrust } \\
(\mathrm{kN})\end{array}$ \\
\hline \multicolumn{7}{|c|}{ Heritage Cermet (ANL) } \\
\hline ANL-200 & 17.5 & 60.96 & 121 & 5.40 & 178 & 39.6 \\
\hline ANL-2000 & 37.3 & 60.96 & 187 & 16.5 & 1610 & 357.0 \\
\hline \multicolumn{7}{|c|}{ Heritage Cermet (GE-710) } \\
\hline GE-710 & 18.0 & 60.96 & 169 & 13.5 & 453 & 100.7 \\
\hline \multicolumn{7}{|c|}{ Pratt \& Whitney Cermet } \\
\hline XNR-2000-A & 32.0 & 60.96 & 253 & 11.4 & 853 & 189.8 \\
\hline XNR-2000-B & 24.0 & 60.96 & 139 & 9.41 & 469 & 104.4 \\
\hline Proprietary & 20.0 & 60.96 & 61 & 5.41 & 206 & 45.7 \\
\hline ESCORT & 25.5 & 60.96 & 109 & 3.52 & 193 & 43.0 \\
\hline \multicolumn{7}{|c|}{ Heritage NERVA Geometry } \\
\hline NE-X & 17.0 & 60.96 & 256 & $5.40^{*}$ & 179 & 39.9 \\
\hline
\end{tabular}

\subsection{Neutronics Results for Fast Spectrum Reactors in the 111.2 kN (25,000-lb $\left.b_{f}\right)$ Thrust Class}

As described earlier, the primary motivation for current interest in $111.2 \mathrm{kN}\left(25,000-\mathrm{lb}_{\mathrm{f}}\right)$ class systems is the DRA 5.0 study use of a common nuclear thermal propulsion stage with three $111.2 \mathrm{kN}$ engines for all primary mission maneuvers. In this section, growth versions of the lower thrust configurations are considered. Options to extend the lower thrust designs into the $111.1 \mathrm{kN}$ thrust range include changes in the number of fuel elements and changes in the active fuel length. The approach taken here is to consider combinations of active fuel length and number of fuel elements that can provide the required thermal energy without exceeding the fuel matrix power density in the heritage (or proposed) engine designs. 


\subsubsection{Configurations Based on ANL Heritage Cermet Designs}

Characteristics of selected configurations with cores made up using the fuel element from the heritage ANL-200 design are shown in Table 11. The first set is a simple radial growth version containing 349 fuel elements while retaining the 60.96-cm (24.00-in) active fuel length. Credit for considerable excess reactivity is taken by reducing the ${ }^{235} \mathrm{U}$ enrichment to $60 \mathrm{wt} \%$. Calculated control swing for the $28.5-\mathrm{cm}$ radius core with a thin radial reflector is marginal at $\sim 2.7 \$$. Even if the low value persists when control drums are explicitly modeled, small changes to optimize the configuration can be expected to raise the calculated control swing worth.

For the second set the active fuel length is increased to $86.36 \mathrm{~cm}(34.00 \mathrm{in})$. The core radius is reduced to $24.0 \mathrm{~cm}$ and contains 241 fuel elements. The ${ }^{235} \mathrm{U}$ enrichment is $70 \mathrm{wt} \%$. Core masses are comparable to the first set and control swings are improved, but the ${ }^{235} \mathrm{U}$ content is higher.

The active fuel length is increased to $121.92 \mathrm{~cm}(48.00 \mathrm{in})$ for the third set. The core radius is reduced to $21.0 \mathrm{~cm}$ and contains 169 fuel elements. As with the second set, the ${ }^{235} \mathrm{U}$ enrichment is $70 \mathrm{wt} \%$. Core masses are increased compared to the second set and ${ }^{235} \mathrm{U}$ masses are comparable.

The ${ }^{235} \mathrm{U}$ masses are high for all configurations. None of the configurations are optimized. Future efforts will likely be focused around the shorter configurations in the first set. These efforts will be deferred pending conclusions from the NASA GRC thermal and systems level evaluations in progress.

Table 11: Characteristics of selected reactor configurations based on the ANL-200 heritage cermet fuel design.

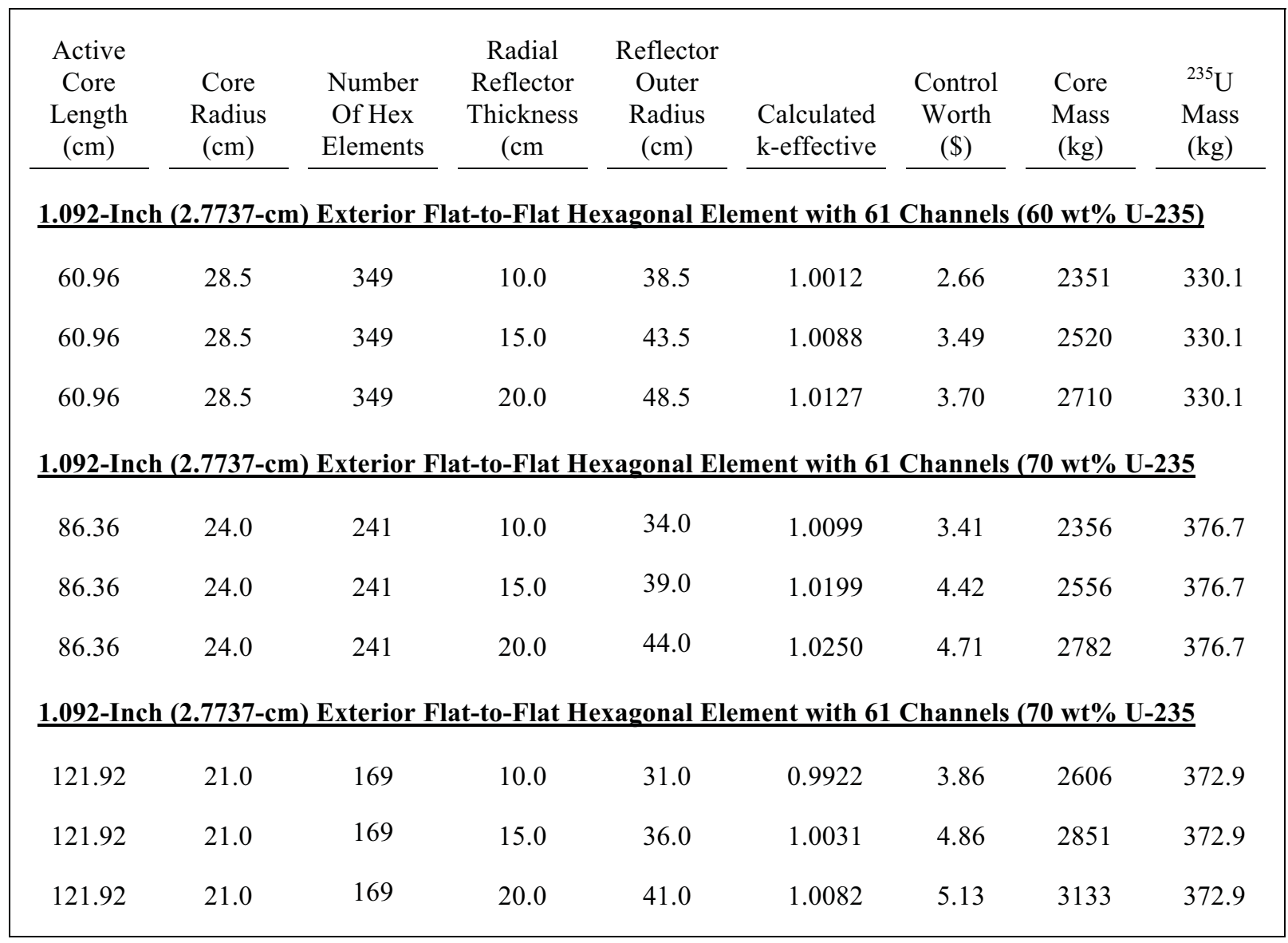




\subsubsection{Configurations Based on the GE-710 Heritage Cermet Design}

Characteristics of selected configurations with cores made up using the fuel element from the heritage GE-710 design are shown in Table 12. Credit for excess reactivity is taken by reducing the ${ }^{235} \mathrm{U}$ enrichment. The enrichment is different in each set. Calculated control swings appear adequate for all cases. Compared to the ANL-200 based configurations, core masses are reduced by about a factor of two and ${ }^{235} \mathrm{U}$ inventories are about one-third lower. None of the configurations are optimized and additional efforts will be deferred pending conclusions from the NASA GRC thermal and systems level evaluations in progress.

Table 12: Characteristics of selected reactor configurations based on the GE-710 heritage cermet fuel design.

\begin{tabular}{|c|c|c|c|c|c|c|c|c|}
\hline $\begin{array}{l}\text { Active } \\
\text { Core } \\
\text { Length } \\
(\mathrm{cm})\end{array}$ & $\begin{array}{l}\text { Core } \\
\text { Radius } \\
(\mathrm{cm})\end{array}$ & $\begin{array}{l}\text { Number } \\
\text { Of Hex } \\
\text { Elements }\end{array}$ & $\begin{array}{c}\text { Radial } \\
\text { Reflector } \\
\text { Thickness } \\
\text { (cm }\end{array}$ & $\begin{array}{l}\text { Reflector } \\
\text { Outer } \\
\text { Radius } \\
(\mathrm{cm})\end{array}$ & $\begin{array}{l}\text { Calculated } \\
\text { k-effective }\end{array}$ & $\begin{array}{l}\text { Control } \\
\text { Worth } \\
(\$)\end{array}$ & $\begin{array}{l}\text { Core } \\
\text { Mass } \\
(\mathrm{kg})\end{array}$ & $\begin{array}{c}{ }^{235} \mathrm{U} \\
\text { Mass } \\
(\mathrm{kg})\end{array}$ \\
\hline \multicolumn{9}{|c|}{ 0.9276-Inch (2.3561-cm) Exterior Flat-to-Flat Hexagonal Element with 91 Channels (80 wt\% U-235) } \\
\hline 55.88 & 20.2 & 241 & 10.0 & 30.2 & 0.9877 & 3.80 & 1301 & 203.0 \\
\hline 55.88 & 20.2 & 241 & 15.0 & 35.2 & 0.9992 & 5.04 & 1427 & 203.0 \\
\hline 55.88 & 20.2 & 241 & 20.0 & 40.2 & 1.0051 & 5.41 & 1572 & 203.0 \\
\hline \multicolumn{9}{|c|}{ 0.9276-Inch (2.3561-cm) Exterior Flat-to-Flat Hexagonal Element with 91 Channels (85 wt\% U-235) } \\
\hline 71.12 & 18.0 & 187 & 10.0 & 28.0 & 0.9896 & 4.61 & 1308 & 213.0 \\
\hline 71.12 & 18.0 & 187 & 15.0 & 33.0 & 1.0037 & 6.09 & 1450 & 213.0 \\
\hline 71.12 & 18.0 & 187 & 20.0 & 38.0 & 1.0107 & 6.55 & 1615 & 213.0 \\
\hline \multicolumn{9}{|c|}{ 0.9276-Inch $(2.3561-\mathrm{cm})$ Exterior Flat-to-Flat Hexagonal Element with 91 Channels $(90 \mathrm{wt} \% \mathrm{U}-235)$} \\
\hline 86.36 & 16.2 & 151 & 10.0 & 26.2 & 0.9825 & 5.45 & 1287 & 221.1 \\
\hline 86.36 & 16.2 & 151 & 15.0 & 31.2 & 0.9994 & 7.23 & 1444 & 221.1 \\
\hline 86.36 & 16.2 & 151 & 20.0 & 36.2 & 1.0080 & 7.86 & 1628 & 221.1 \\
\hline
\end{tabular}

\subsection{Preliminary Estimates of System Level Performance for 111.2 kN (25,000-Ibf) Class Configurations}

Results reported in the previous section are from the initial set of performance evaluations. Configurations are critical and appear to have adequate control swing. Fuel element and system level performance are to be evaluated by NASA GRC. Preliminary estimates of allowable core thermal power can be made based on power density considerations and preliminary estimates of engine thrust level can be made by simple thermal power scaling from heritage designs. Results of these preliminary estimates are shown in Table 13. 
Table 13: Preliminary estimates of system level performance for $111.2 \mathrm{kN}(25,000$-lbf) class configurations.

\begin{tabular}{|c|c|c|c|c|c|c|c|c|c|}
\hline $\begin{array}{l}\text { Active } \\
\text { Core } \\
\text { Length } \\
(\mathrm{cm})\end{array}$ & $\begin{array}{c}\text { Core } \\
\text { Radius } \\
(\mathrm{cm})\end{array}$ & $\begin{array}{c}\text { Reflector } \\
\text { Outer } \\
\text { Radius } \\
(\mathrm{cm})\end{array}$ & $\begin{array}{l}\text { Number } \\
\text { Of Hex } \\
\text { Elements }\end{array}$ & $\begin{array}{l}\text { Fuel } \\
\mathrm{Wt} \% \\
{ }^{235} \mathrm{U}\end{array}$ & $\begin{array}{c}\text { Core } \\
\text { Mass } \\
(\mathrm{kg})\end{array}$ & $\begin{array}{c}{ }^{235} \mathrm{U} \\
\text { Mass } \\
(\mathrm{kg})\end{array}$ & $\begin{array}{c}\text { Fuel } \\
\text { Matrix } \\
\text { Power } \\
\text { Density } \\
\text { (MW/liter) }\end{array}$ & $\begin{array}{l}\text { Core } \\
\text { Power } \\
(\mathrm{MW})\end{array}$ & $\begin{array}{c}\text { Engine } \\
\text { Thrust } \\
(\mathrm{kN})\end{array}$ \\
\hline
\end{tabular}

\subsection{2-Inch (2.7737-cm) Exterior Flat-to-Flat Hexagonal Element with 61 Channels (ANL-200)}

$\begin{array}{rrrrrrrrrr}60.96 & 17.5 & 27.5 & 121 & 93 & 1000 & 177.3 & 5.40 & 178 & 39.6 \\ 60.96 & 28.5 & 43.5 & 349 & 60 & 2520 & 330.1 & 5.40 & 513 & 114.1 \\ 86.36 & 24.0 & 34.0 & 241 & 70 & 2356 & 376.7 & 5.40 & 502 & 111.6 \\ 121.92 & 21.0 & 31.0 & 169 & 70 & 2606 & 372.9 & 5.40 & 497 & 110.5\end{array}$

1.930-Inch (4.9022-cm) Exterior Flat-to-Flat Hexagonal Element with 331 Channels (ANL-2000)

$\begin{array}{llllllllll}60.96 & 37.3 & 52.3 & 187 & 93 & 3946 & 523.7 & 16.5 & 1610 & 357.0\end{array}$

0.9276-Inch (2.3561-cm) Exterior Flat-to-Flat Hexagonal Element with 91 Channels (GE-710)

$\begin{array}{rrrrrrrrrr}60.96 & 18.0 & 33.0 & 169 & 93 & 1297 & 180.5 & 13.5 & 453 & 100.7 \\ 55.88 & 20.2 & 35.2 & 241 & 80 & 1427 & 203.0 & 13.5 & 592 & 131.6 \\ 71.12 & 18.0 & 33.0 & 187 & 85 & 1450 & 213.0 & 13.5 & 584 & 130.0 \\ 86.36 & 16.2 & 31.2 & 151 & 90 & 1444 & 221.1 & 13.5 & 573 & 127.4\end{array}$

$\underline{1.40-I n c h ~(3.5560-c m) ~ E x t e r i o r ~ F l a t-t o-F l a t ~ H e x a g o n a l ~ E l e m e n t ~ w i t h ~} 169$ Channels (P\&W XNR-2000A) $\begin{array}{llllllllll}60.96 & 32.0 & 47.0 & 253 & 93 & 3067 & 403.0 & 11.4 & 853 & 189.8\end{array}$

1.40-Inch (3.5560-cm) Exterior Flat-to-Flat Hexagonal Element with 37 Channels (P\&W XNR-2000B) $\begin{array}{llllllllll}60.96 & 24.0 & 34.0 & 139 & 93 & 1604 & 268.6 & 9.41 & 469 & 104.4\end{array}$

Proprietary Element Design Providing Growth Path to Bimodal and Trimodal Designs (P\&WR)

$\begin{array}{llllllllll}60.96 & 20.0 & 30.0 & 61 & 93 & 1296 & 204.5 & 5.41 & 206 & 45.7\end{array}$

1.70-Inch Exterior Flat-to-Flat Hexagonal Element with 48 Channels (P\&W ESCORT and TRITON) $\begin{array}{llllllllll}60.96 & 25.5 & 40.5 & 109 & 93 & 2076 & 295.5 & 3.52 & 193 & 43.0\end{array}$

0.75-Inch (1.9050-cm) Exterior Flat-to-Flat Hexagonal Element with 19 Channels (NERVA Geometry) $\begin{array}{llllllllll}60.96 & 17.0 & 27.0 & 256 & 93 & 857 & 178.7 & 5.40 * & 179 & 39.9\end{array}$

* No specific engine design proposed; assumed power density from ANL-200 with similar fuel web thickness but different fuel volume fractions 


\section{Concluding Observations and Status of Analyses}

This report documents the status of evaluations focused on reactor designs suitable for nuclear thermal propulsion systems. Both thermal neutron spectrum systems using graphite based fuels and fast neutron spectrum systems using refractory metal alloy fuels are being evaluated at two different thrust levels. The larger systems are in the $111.2 \mathrm{kN}(25,000-\mathrm{lbf})$ class identified in the recent NASA Design Reference Architecture (DRA) 5.0 Study. Also examined are smaller lower thrust systems considered more attractive for an in-space nuclear propulsion technology demonstrator prior to larger scale use for cargo and crewed human exploration missions. An important goal is that the lower thrust designs demonstrate the critical technologies that are directly extensible to higher thrust systems.

Thermal neutron spectrum engine configurations evaluated in this effort are based on extensions of the Small Nuclear Rocket Engine (SNRE) design to higher and to lower thrust levels. All are fueled using $(\mathrm{U}, \mathrm{ZrC}) \mathrm{C}$-graphite composite fuel. Extensibility is achieved by using the same reactor core element designs at both thrust levels.

Fast spectrum systems were evaluated using eight fuel element designs from heritage and from more recently proposed designs. All are fueled using the most promising fuel composition from the ANL heritage program. Extensibility is achieved by using common fuel element designs at both thrust levels. Preliminary estimates of system level performance have been completed using approximate methods.

Analyses being conducted in three closely coupled areas (neutronics, multiphysics, and system level engine performance) are in various stages for the two reactor types (thermal and fast neutron spectrum) at the two thrust levels. The status of the analyses is summarized in Table 14.

Table 14: Status of analyses by analysis phase, reactor type, and thrust level.

\begin{tabular}{|c|c|c|c|c|}
\hline \multirow[b]{2}{*}{ Analysis Phase } & \multicolumn{2}{|c|}{$\begin{array}{l}\text { Composite-Fueled } \\
\text { Thermal Spectrum Cores }\end{array}$} & \multicolumn{2}{|c|}{$\begin{array}{l}\mathrm{W}-\mathrm{UO}_{2}-\mathrm{Gd}_{2} \mathrm{O}_{3}-\text { Fueled } \\
\text { Fast Spectrum Cores }\end{array}$} \\
\hline & $\begin{array}{c}\text { Technology } \\
\text { Demonstrator } \\
\text { Class }\end{array}$ & $\begin{array}{c}111.2 \mathrm{kN} \\
\left(25,000 \mathrm{lb}_{\mathrm{f}}\right) \\
\text { Class }\end{array}$ & $\begin{array}{c}\text { Technology } \\
\text { Demonstrator } \\
\text { Class }\end{array}$ & $\begin{array}{c}111.2 \mathrm{kN} \\
\left(25,000 \mathrm{lb}_{\mathrm{f}}\right) \\
\text { Class }\end{array}$ \\
\hline Initial Neutronics & Completed & Completed & 8 of 8 & 2 of 8 \\
\hline Core Element Multiphysics & Completed & Completed & In Progress & Pending \\
\hline Engine System Level (NESS) & Completed & Completed & In Progress & Pending \\
\hline Refined In-Class Neutronics & Completed & Completed & Pending & Pending \\
\hline Multiphysics \& Engine System & Completed & Completed & Pending & Pending \\
\hline Optimized In-Class Neutronics & Pending & Pending & Pending & Pending \\
\hline Multiphysics \& Engine System & Pending & Pending & Pending & Pending \\
\hline Optimized Neutronics (Cross-Class) & Pending & Pending & Pending & Pending \\
\hline Multiphysics \& Engine System & Pending & Pending & Pending & Pending \\
\hline
\end{tabular}


Neutronics performance evaluations for the thermal spectrum cores at both thrust levels have been completed for both the initial configurations and for configurations incorporating improved core neutronics performance. Combined thermal hydraulic and structural (multiphysics) and system level engine performance analyses have also been completed. Additional optimization within each thrust level is pending.

Neutronics performance has been evaluated for eight fast spectrum criticality limited reactor configurations made up of eight different fuel element designs. Multiphysics and system level engine performance evaluations are in progress at NASA GRC. Neutonics evaluations have been completed for extensions to higher thrust levels for two of the designs. Extensions to higher thrust levels for other promising candidates in the set are pending.

\section{Plans and Recommendations for Continuing Work}

Results from neutronic analyses of the remaining six fast spectrum reactor cores will be provided to NASA GRC as input to integrated thermal-fluid-structural analyses of the core components and as input for system level performance analyses. Core modifications to extend selected designs to the $111.2 \mathrm{kN}$ $\left(25,000-1 b_{f}\right)$ thrust level will be performed pending completion of thermal and system level evaluations for the criticality limited configurations.

Two important issues should be addressed to guide the selection of the most promising candidates among the fast spectrum engine concepts. Completion of fuel element thermal performance evaluation is a critical step in establishing allowable fuel matrix power density and ultimately engine system performance. The importance of somewhat high ${ }^{235} \mathrm{U}$ inventories should be prioritized. Recognition of specific ${ }^{235} \mathrm{U}$ limitations could exclude consideration of some of the concepts and could profitably guide resource allocations among the fuel candidate development efforts.

The sensitivities to other cermet fuel compositions and other clad compositions will be evaluated. Including specific materials in the core to soften the neutron spectrum has been suggested as a possible means of reducing the ${ }^{235} \mathrm{U}$ inventory required. The effectiveness of spectral softening will be evaluated.

Optimization of the thermal spectrum concepts will be performed within each of the two thrust classes. Any constraints on the optimization process that are imposed by extensibility requirements will be identified. The question of what constitutes an adequate demonstration of extensibility should be considered. 


\section{References}

${ }^{1}$ Human Exploration of Mars Design Reference Architecture, SP-2009-566, NASA, July 2009.

${ }^{2}$ National Space Policy of the United States, 28 June 2010.

${ }^{3}$ Daniel R. Koenig, "Experience Gained from the Space Nuclear Rocket Program (Rover)", Los Alamos National Laboratory, Report LA-10062-H, Los Alamos, NM, May 1986.

${ }^{4} 710$ High-Temperature Gas Reactor Program Summary Report, General Electric, Report GEMP-600 Volume 1, Cincinnati, OH, 1968.

${ }^{5}$ Nuclear Rocket Program Terminal Report, Argonne National Laboratory, Report ANL-7236, Argonne, IL, 1968.

${ }^{6}$ S. K. Bhattacharyya, "An Assessment of Fuels for Nuclear Thermal Propulsion", Argonne National Laboratory, Report ANL/TD/TM01-22, Argonne, IL, December 2001.

${ }^{7}$ X-5 Monte Carlo Team, "MCNP - A General Monte Carlo N-Particle Transport Code, Version 5", Los Alamos National Laboratory, Report LA-UR-03-1987, Los Alamos, NM, April 2003.

${ }^{8}$ D. Garber, (Editor), "Evaluated Nuclear Data File (ENDF/B-V)", National Nuclear Data Center, Brookhaven National Laboratory Report BNL-17541, October 1975.

${ }^{9}$ V. McLane, C. L. Dunford, and P. F. Rose, (Editors), "ENDF-102, Data Formats and Procedures for the Evaluated Nuclear Data File ENDF-6 (Revised)", Brookhaven National Laboratory Report BNLNCS-44945, November 1995.

${ }^{10}$ R. J. Howerton, et al., "The LLL Evaluated Nuclear Data Library (ENDL): Evaluation Techniques, Reaction Index, and Descriptions of Individual Reactions", Lawrence Livermore National Laboratory Report UCRL-50400, Volume 15, Part A, September 1975.

${ }^{11}$ James A. Dewar, To the End of the Solar System: The Story of the Nuclear Rocket, Apogee Books, 2007.

${ }^{12}$ W. H. Robbins and H. B. Finger, "An Historical Perspective of the NERVA Nuclear Rocket Engine Technology Program”, AIAA-91-3451, July 1991.

${ }^{13}$ N Division Personnel, "Pewee 1 Reactor Test Report", Los Alamos National Laboratory, Report LA4217-MS, Los Alamos, NM, August 1969.

${ }^{14}$ W. L. Kirk, "Nuclear Furnace-1 Test Report", Los Alamos National Laboratory, Report LA-5189MS, Los Alamos, NM, March 1973.

${ }^{15}$ J. M. Taub, "A Review of Fuel Element Development for Nuclear Rocket Engines", Los Alamos National Lab., Report LA-5931, Los Alamos, NM, June 1975.

${ }^{16}$ L. L. Lyon, "Performance of (U,Zr)C-Graphite (Composite) and of (U,Zr)C (Carbide) Fuel Elements in the Nuclear Furnace 1 Test Reactor", Los Alamos National Laboratory. Report LA-5398-MS, Los Alamos, NM, Sept 1973.

${ }^{17}$ F. P. Durham, "Nuclear Engine Definition Study Preliminary Report, Volume 1 - Engine Description", Los Alamos National Laboratory, Report LA-5044-MS Vol 1, Los Alamos, NM, Sept 1972

${ }^{18}$ F. P. urham, "Nuclear Engine Definition Study Preliminary Report, Volume 2 - Supporting Studies", Los Alamos National Laboratory, Report LA-5044-MS Vol 2, Los Alamos, NM, Sept 1972.

${ }^{19}$ Bruce G. Schnitzler and Stanley K. Borowski, "Neutronics Models and Analysis of the Small Nuclear Rocket Engine (SNRE)", AIAA-2007-5618, July 2007.

${ }^{20}$ Bruce G. Schnitzler and Stanley K. Borowski, "Enrichment Zoning Options for the Small Nuclear Rocket Engine (SNRE)", AIAA-2010-6816, July 2010.

${ }^{21}$ Bruce G. Schnitzler and Stanley K. Borowski, "Small Nuclear Rocket Engine and Stage Benchmark Model", AIAA-2008-4949, July 2008.

${ }^{22}$ Mark E. M. Stewart and Bruce G. Schnitzler, "Thermal Hydraulic and Structural Analysis of Nuclear Thermal Propulsion Core Components", AIAA-2008-4950, July 2008. 
${ }^{23}$ James E. Fittje and Bruce G. Schnitzler, "Evaluation of Recent Upgrades to the NESS (Nuclear Engine System Simulation) Code", AIAA-2008-4951, July 2008.

${ }^{24}$ Bruce G. Schnitzler and Stanley K. Borowski, "25,000-lb f $_{\mathrm{f}}$ Thrust Engine Options Based on the Small Nuclear Rocket Engine Design”, AIAA-2009-5239, August 2009.

${ }^{25}$ L. W. Carlson, et al., "CERMET Fueled Reactors for Direct Nuclear Thermal Propulsion”, AL-TR-89-007, Argonne National Laboratory, Argonne, IL, July 1989.

${ }^{26}$ R. C. Parsley, "Advanced Propulsion Engine Assessment Based on A CERMET Reactor", NASA Conference Publication 10116, Nuclear Propulsion Technology Interchange Meeting, October 1992.

${ }^{27}$ C. Russell Joyner, "The Synergistic Application of Chemical Rocket Component Technologies to the ESCORT Nuclear Bimodal System”, AIAA-2000-3211, July 2000.

${ }^{28}$ C. Russell Joyner, et al., "TRITON: A TRImodal Thrust Optimized Nuclear Propulsion and Power System for Advanced Space Missions", AIAA-2004-3863, July 2004.

${ }^{29}$ C. Haertling and R. J. Hanrahan Jr., "Literature review of thermal and radiation performance parameters for high-temperature, uranium dioxide fueled cermet materials", Journal of Nuclear Materials Volume 366, pages 317 - 355, 2007. 